\title{
The Impact of the COVID-19 Movement Restrictions on the Road Traffic in the Czech Republic during the State of Emergency
}

\author{
Milan Simunek, Zdenek Smutny $(\mathbb{D}$, and Michal Dolezel 1 i \\ Faculty of Informatics and Statistics, Prague University of Economics and Business, W. Churchill Sq. 1938/4, Prague, \\ Czech Republic
}

Correspondence should be addressed to Zdenek Smutny; zdenek.smutny@vse.cz

Received 4 December 2020; Revised 27 March 2021; Accepted 30 March 2021; Published 21 April 2021

Academic Editor: Avinash Unnikrishnan

Copyright $(92021$ Milan Simunek et al. This is an open access article distributed under the Creative Commons Attribution License, which permits unrestricted use, distribution, and reproduction in any medium, provided the original work is properly cited.

The COVID-19 pandemic crisis has impacted numerous areas of people's work and free-time activities. This article aims to present the main impacts of the COVID-19 movement restrictions on the road traffic in the Czech Republic, measured during the first epidemic wave, i.e., from 12 March to 17 May 2020. The state of emergency was imposed by the Czech government as a de jure measure for coping with the perceived crisis, although the measure eventually resulted only in a quite liberal de facto form of stayat-home instruction. Unique country-scale traffic data of the first six months of 2020 from $37,002 \mathrm{~km}$ of roads, constituting $66 \%$ of all roads in the Czech Republic, were collected and analyzed. For the prediction of the prepandemic traffic conditions and their comparison with the measured values in the period of the state of emergency, a long-term traffic speed prediction ensemble model consisting of case-based reasoning, linear regression, and fallback submodels was used. The authors found out that the COVID-19 movement restrictions had a significant impact on the country-wide traffic. Traffic density was reduced considerably in the first three weeks, and the weekly average traffic speed in all road types increased by up to $21 \%$, expectedly due to less crowded roads. The exception was motorways, where a different trend in traffic was found. In sum, during the first three weeks of the state of emergency, people followed government regulations and restrictions and changed their travel behavior accordingly. However, following this period, the traffic gradually returned to the prepandemic state. This occurred three weeks before the state of emergency was terminated. From a behavioral perspective, this article briefly discusses the possible causes of such discrepancies between de jure and de facto pandemic measures, i.e., the governmental communication strategy related to loosening of movement restrictions, media reality, and certain culture-related traits.

\section{Introduction}

The COVID-19 pandemic crisis has resulted in an unprecedented impact on societies all over the world. The majority of the world population has been forced to dramatically change their patterns of behavior with regard to the number of daily activities they had previously thought of as automatic or common. In the period of the COVID-19 pandemic culmination (i.e., Spring 2020), many countries issued various measures and stay-at-home instructions. They did so in an attempt to minimize further the spread of the disease by reducing people's mobility. In terms of rigor, these measures differed significantly among various countries and political regimes [1]. In this situation, employers commonly encouraged (or explicitly required) their employees to use teleworking capabilities and work from home [2]. Also, leisure activities requiring commuting were frequently waived. Overall, the need for moving around in cars or for taking public transport was significantly reduced. On the other hand, people were increasingly willing to walk and cycle in the proximity of their homes [3]. In addition, it can be stated that the COVID-19 pandemic has impacted both the physical and the virtual environment (see, e.g., [4-6]).

All these measures had a significant impact on urban and country road traffic speed and density. In this article, we present our findings by characterizing the traffic-related impact that the COVID-19 pandemic caused in the Czech Republic, a Central European country with a population of 10.7 million inhabitants. We carried out a traffic speed 
analysis to study the impact of specific conditions on this indicator (see, e.g., $[7,8]$ ). A traffic prediction model was also created to estimate traffic speed based on historical data of road segments, as if there had been no restrictions due to the COVID-19 pandemic. Real traffic information acquired for the period of applicable governmental restrictions was compared to these results. In our case, the influence of the COVID-19 stay-at-home measures adopted in the Czech Republic was examined.

Our study uses whole-country data for the Czech Republic collected in 2020 from the Road and Motorway Directorate of the Czech Republic and provided for research purposes. The obtained traffic information for individual road segments combines Floating Car Data (FCD) and data from other traffic sensors (see Methodology). This is the most complete traffic dataset for the Czech Republic that reflects traffic for the first 6 months of 2020 .

In the Czech Republic, the first confirmed cases of COVID-19 infection were recorded at the beginning of March 2020 and the state of emergency was declared already on 12 March and terminated on 17 May 2020 (see Section 2.1). The analysis focuses on the period of 24 February 2020-7 June 2020. This article thus deals with the first epidemic wave of COVID-19 in the Czech Republic. To compare the trends, extra weeks were considered before and after this state of emergency period. Therefore, the data obtained during the state of the emergency period can be contrasted with the data that preceded and followed this period, respectively.

For the purposes of this research, the following main analytical question (AQ) was determined, comprising several partial subquestions:

AQ 1. What was the impact of the COVID-19 antiepidemic measures on the road traffic related to different types of roads in the Czech Republic?

AQ 1.1. How did traffic speed (and thus traffic density) vary in time during the individual weeks of the state of emergency?

AQ 1.2. How did traffic speed (and thus traffic density) vary across the various road types?

$A Q$ 1.3. What was traffic development like during Easter (10-13 April 2020 inclusive)?

In connection with AQ 1.3., it should be noted that besides Christmas, Easter is the most important holiday in the Czech Republic. Easter is a moveable feast in the Christian tradition and a traditional holiday in the Czech Republic. The Easter holidays in 2020 were from 10 April to 13 April.

When determining traffic density, it is assumed that the continuously reduced speed used for passing a given road segment increases traffic density and traffic congestion degree in the given road segment. Due to this assumption, the authors focused on traffic speed analysis in selected segments and in selected periods, for which traffic information is available from the Road and Motorway Directorate of the Czech Republic.
The remainder of the article is structured as follows. Section 2 reviews previous literature on COVID-19's impact on traffic and transportation. Section 3 describes the research approach adopted. The findings are presented in Section 4 . Section 5 discusses and concludes the article.

\section{Background}

2.1. COVID-19 Infection in the Czech Republic. In the Czech Republic, the first three COVID-19 cases were confirmed on 1 March 2020. The disease continued to spread over the country and 3,314 cases were reported by the end of March 2020 [9]. Anecdotally, the spread of the disease was ascribed to the Czech tourists returning from Italy, where they had spent their winter holiday.

The response of Czech government officials was extremely rapid, following the steady growth of COVID-19 cases. As there were 95 cases reported in total by $11 \mathrm{March}$ 2020, concrete measures and restrictions were adopted piecemeal as follows. On $12 \mathrm{March}$, the state of emergency was declared. Following this, the majority of shops and public facilities were forced to close on 14 March. As of 16 March, the country closed its borders. On 15 March, Resolution No. 215: Crisis Measure Banning Free Movement of Persons was adopted (with several exceptions, such as commuting, however, the measure also included the recommendation for employers to favor remote work as much as possible).

To further outline in more detail how the antiepidemic measures gradually unfolded, the key milestones are summarized in Table 1 based on the official, continuously published measures adopted by the Government $(G)$ and the Ministry of Health (MH) of the Czech Republic [10]. To acknowledge an important contextual factor, the readers should note that the Easter holidays were from 10 to 13 April 2020 (inclusive).

Figure 1 illustrates the gradual decrease in the number of infected people as of the end of March 2020. The number of detected cases of COVID-19 infection decreases rapidly around 11 April 2020, as this is the period of the Easter holidays, and so fewer people get tested.

Figure 1 also shows the results of the Apple Mobility Trends Reports focused only on driving. Initial rapid drop in traffic after 11 March 2020 can be seen in Figure 1 and the initial development is comparable to our results in Section 4. The Apple Mobility Trends Reports offer daily anonymized and aggregated data on the relative volume of requests for driving directions on Apple Maps. 13 January 2020 (Monday) was chosen as a baseline (100\%, normal or prepandemic traffic) by Apple because it was a fortnight before the World Health Organization declared COVID-19 as a public health emergency of international concern on 30 January 2020 [12]. Therefore, this day the data could not be affected by the events around COVID-19 and at the same time, it is a day with average traffic.

The disadvantage of Apple data is that they do not distinguish among different road types. These data are also incomplete for some regions of the Czech Republic, which may be due to the low penetration (only 25\%) of Apple 
TABLE 1: Key resolutions and antiepidemic measures (only key ones are listed; "effective to" dates were omitted, as the measures were repeatedly extended).

\begin{tabular}{|c|c|c|}
\hline Issued on (administrative number) & Effective from & Key antiepidemic measures \\
\hline 12 March 2020 (G no. 194) & $\begin{array}{l}12 \text { March } 20202 \text { : } \\
00 \text { p.m. }\end{array}$ & Declaration of the state of emergency in the territory of the Czech Republic \\
\hline 12 March 2020 (G no. 200) & 14 March 0:00 & $\begin{array}{l}\text { Prohibition of international passenger transport using vehicles with a capacity of } \\
\text { more than } 9 \text { passengers (however, the occasional return to the Czech Republic by } \\
\text { means of vehicles with a capacity of more than } 9 \text { passengers is allowed, as well as } \\
\text { transportation of empty buses back) }\end{array}$ \\
\hline 12 March 2020 (G no. 201) & 13 March 0:00 & $\begin{array}{c}\text { School closure, i.e., "prohibition of school attendance in person by pupils and } \\
\text { students" }\end{array}$ \\
\hline 13 March 2020 (G no. 203) & 16 March 0:00 & Czech borders close \\
\hline 13 March 2020 (G no. 205) & Not stated & $\begin{array}{c}\text { Cancellation of Sunday's lorry ban, which had been permanently effective until } \\
\text { then }\end{array}$ \\
\hline 13 March 2020 (G no. 208) & 14 March 6:00 & $\begin{array}{c}\text { Prohibition of selected leisure activities (e.g., presence at swimming pools and } \\
\text { sports venues) and of selling on the markets }\end{array}$ \\
\hline 14 March 2020 (G no. 211) & 14 March 6:00 & $\begin{array}{r}\text { Prohibition of retail sales and } 1 \\
\text { grocer }\end{array}$ \\
\hline 15 March 2020 (G no. 215) & 16 March 0:00 & $\begin{array}{r}\text { Prohibition of free movement of persc } \\
\text { business travel, dealing with family-re } \\
\text { natu }\end{array}$ \\
\hline Local antiepidemic measure & 16 March 0:00 & $\begin{array}{l}\text { Quarantine order and closure of } \\
\text { prohibition of free mo }\end{array}$ \\
\hline 18 March 2020 (G no. 247) & 19 March 0:00 & $\begin{array}{c}\text { Obligation to use face masks (or similar coverings) in the entire territory of the } \\
\text { Czech Republic }\end{array}$ \\
\hline $\begin{array}{l}23 \text { March } 2020 \text { (G no. } 279, \text { MH no. } \\
12745 / 2020-1)\end{array}$ & 24 March 6:00 & Recommendation for employers to embrace work-from-home solutions \\
\hline 6 April 2020 (MH no. 15190) & $\begin{array}{l}7 \text { April 0:00/9 } \\
\text { April 0:00 }\end{array}$ & $\begin{array}{c}\text { Commencement of loosening of restrictions (DIY retail stores and building } \\
\text { supply stores were reopened (as of } 9 \text { April), as well as bicycle repair shops, } \\
\text { homeware stores, etc.; outside sports venues reopened) }\end{array}$ \\
\hline 15 April 2020 (MH no. 16195) & 20 April 0:00 & Permission to hold small weddin \\
\hline 23 April 2020 (G no. 452) & 24 April 0:00 & $\begin{array}{c}\text { Loosening of restriction of free movement of persons (Meeting was possible for } \\
\text { groups of up to } 10 \text { persons) }\end{array}$ \\
\hline 23 April 2020 (G no. 453) & 27 April 0:00 & Reopening of $b$ \\
\hline 30 April 2020 (G no. 490, 493) & 11 May 0:00 & $\begin{array}{l}\text { Reopening of larger business premises; permission to hold cultural and religious } \\
\text { events and sports activities of up to } 100 \text { persons; allowing only outdoor restaurant } \\
\text { patios }\end{array}$ \\
\hline $30 \mathrm{Ap}$ & 18 May 0:00 & \\
\hline $\begin{array}{l}\text { 18 May } 2020 \text { (G no. } 555 \text { Annex 1, } \\
\text { 2) }\end{array}$ & 25 May 0:00 & $\begin{array}{l}\text { Permission to hold cultural and religious events and sports activities of up to } 300 \\
\text { persons; restaurants reopened between } 6 \text { a.m. and } 11 \text { p.m. }\end{array}$ \\
\hline 1 June 2020 (G no. 605 Annex 4) & 8 June 0:00 & $\begin{array}{c}\text { Permission to hold cultural and religious events and sports activities of up to } 500 \\
\text { persons }\end{array}$ \\
\hline 1 June 2020 (G no. 605 Annex 2) & 15 June 0:00 & $\begin{array}{l}\text { Granting permission to travel abroad and back; some remaining restrictions } \\
\text { removed; no considerable impact on schools, since summer holiday period (July- } \\
\text { August) was ahead }\end{array}$ \\
\hline
\end{tabular}

devices with iOS in the Czech population [13]. Therefore, Figure 1 presents summary data for the entire Czech Republic. On the other hand, the Apple data have a strong similarity to Google Community Mobility Reports [12, 14]. In the period from 12 March to 17 May 2020, a strong negative correlation (0.61) was found between numbers of infected people and road traffic, according to Apple Mobility Trends Reports.

\subsection{COVID-19's Influence on Traffic and Transportation.} There is a growing body of knowledge examining the influence of the COVID-19 pandemic on traffic density and volumes. Existing research studies vary highly in terms of their focus and adopted analytical methods. We categorize extant research literature into two interconnected streams.
First, we review the studies focused on analyzing traffic changes during the COVID-19 pandemic. Second, we review studies focused more on the people-centric perspective by outlining the impact of the antipandemic measures on citizen mobility, travel, and driving behavior.

2.2.1. Traffic. Harantová, Hájnik, and Kalašová [15] carried out a study by measuring traffic flows on a selected arterial road in Slovakia, a neighboring country of the Czech Republic. They compared traffic detector data gathered early in April 2020, when the COVID-19 preventive measures in Slovakia were already effective, with respective data from March 2020, i.e., prior to the COVID-19 spread to Slovakia. Overall, the authors found out that average traffic flows decreased. In turn, average speeds increased substantially, 


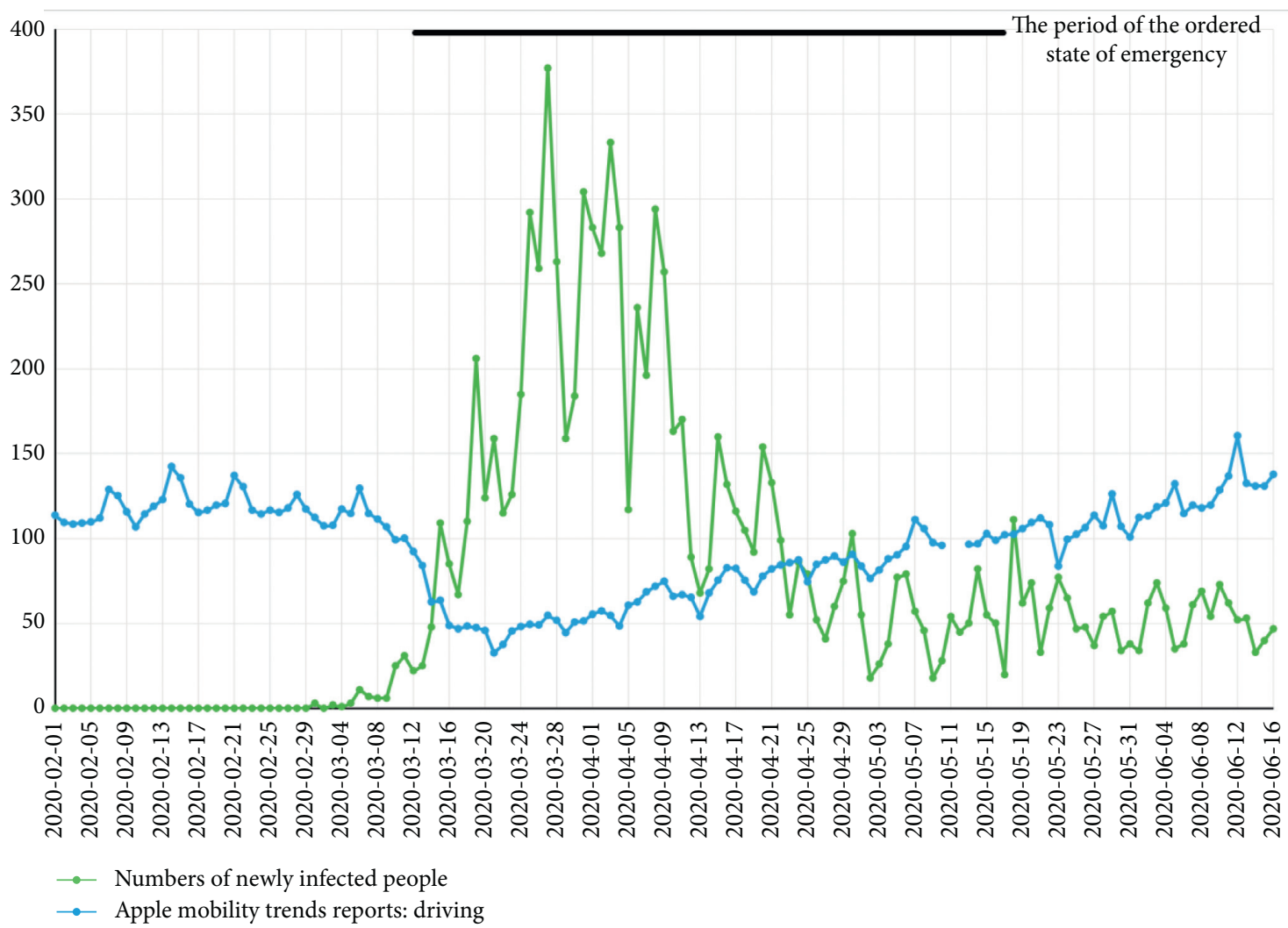

Figure 1: Numbers of newly detected people infected by COVID-19 during the state of emergency and mobility trends according to Apple Maps in the Czech Republic. Source: $[9,11]$.

and, at some road segments, they were also more uniformly distributed throughout the day. These changes have been attributed to the reduction of congestion during the COVID-19 period.

The work of Aletta [16] presented the results of a simulation approach using FCD from vehicles equipped with an On-Board Unit GPS system. During the lockdown period, the traffic in Rome (Italy) was reduced by $64.6 \%$, which had a positive impact on noise emissions reduction. Similarly, Bucsky [17] has shown that the traffic over Danube bridges in Budapest (Hungary) dropped by $37 \%$. Interestingly, he also pointed out that the use of Waze application had a more substantial drop. This was attributed to the absence of congestion, given that the use of applications like Waze is a natural response of people experiencing congestion.

Cui et al. [18] examined both a road segment-level and network-level performance in the Greater Seattle area (United States) and proposed a comprehensive metric traffic performance score to quantify the impact of COVID-19 on urban mobility. The metric is defined as a relative ratio, using free-flow speed as a baseline parameter. Employing this metric, they demonstrated a substantial change in urban traffic patterns following the stay-at-home order. The work of Cui et al. also provided a brief overview of practice-based literature on the COVID-19 traffic impact. Within this category of literature, Marchant [19] provided a good starting point to understand how practitioners and location technology producers quantify the impact of COVID-19 on traffic volumes.
To summarize, different studies have benefitted from different data sources and analytical approaches. While it is hard to derive strong analytical conclusions by comparing the data from different studies, it seems obvious that there was a noticeable effect of the COVID-19 countermeasures and stay-at-home instructions in terms of reduced traffic volumes and density. However, to the best of our knowledge, there is no work that analyzed traffic data at the country- or state-wide level.

\subsubsection{Citizen Mobility, Travel, and Driving Behavior.} Other authors have taken a more holistic perspective, focusing on the differences in people's behavior prior and during the pandemic. For example, Haas, Faber, and Hamersma [20] noted that "people are creatures of habit" and tend to rely on their daily routines. With that in mind, the COVID-19 pandemic has caused a major disruption in those routines, including individual travel behavior. According to the authors, the number of trips decreased considerably (by 55\%) in the Netherlands. In many countries, this was because a large portion of the population suddenly started working from home [21]. Broadly stated, the pandemic crisis has had a significant impact on the distribution among various travel modes. A major shift towards pedestrian and soft mobility (bicycles, scooters, etc.) was observed in some areas [22].

In principle, various data sources can be employed to study the impact of COVID-19 on citizen mobility and travel 
and driving behavior [23]. First, Aloi et al. [24] exploited a number of data sources, including traffic counters, control cameras, and public transport data. They demonstrated a major change in Santander (Spain) citizens' behavior with regard to the purpose of trips and their length. Overall, car mobility decreased by $68 \%$ in the studied area. Next, Jenelius and Cebecauer [25] used data from ticket validations in Stockholm and Västra Götaland (Sweden). They showed how public transport use declined and the sales of certain ticket types dropped to almost zero.

Employing a survey as the main research technique to understand the phenomenon, a number of studies have noted a change in commuter behavior. Examining the situation in different European countries, several surveys are available up to date. A survey performed among Gdańsk (Poland) residents reported that $47 \%$ of respondents stopped using public transport means entirely [26]. Interestingly, some of these behavioral shifts are foreseen to have a longterm impact. For example, in Sicily (Italy), $61 \%$ of respondents estimated that cycling will be more frequently used even post-lockdown.

Based on a survey carried out in India, Pawar et al. [27] found out that $42 \%$ of respondents stopped travelling during the pandemic crisis, and $5 \%$ started using private travel means instead of public ones. Surveys were also carried, for example, in Lagos (Nigeria) [28] and Kanto Region (Japan) [29]. Using panel data, Shakibaei et al. [23] identified interesting patterns in how travelling related to Social/Recreational/Leisure (SRL) changed during three phases of the virus outbreak in Istanbul (Turkey). They argued that currently, the situation regarding travel behavior is "in a stage of flux." That means it is quite hard to estimate how the future will look like in terms of new mobility patterns.

Focusing on additional aspects, some studies have examined changing patterns of consumer behavior related to traffic, including shopping and dining. Analyzing survey data collected in Chicago metropolitan area (Illinois, United States), Shamshiripour et al. [30] found out that the COVID19 pandemic has served as a driver for attracting new customers to use online shopping and online meal ordering. These are the two areas that may directly reduce the needs for individual driving, yet in turn intensify the traffic associated with various delivery services [31]. This can lead to the development of new logistics-oriented applications for optimizing delivery services [32].

The impact of COVID-19 has also been studied from the perspective of traffic safety. A number of negative trends in driving behaviors have been estimated, including more frequent speeding and stunt driving due to the larger amount of free time some people might generally experience [33]. Interestingly, studies that emerge within this domain have started bringing initial evidence that the COVID-19 pandemic may also promote driving more in certain groups of citizens not only due to leisure activities. For example, Stavrinos et al. [34] studied the driving routines of young citizens of Birmingham (Alabama, United States) and pointed out a notable effect of the COVID-19 measures. That is, in certain demographic groups of adolescents, the COVID-19 measures may effectively result in more driving.
In such groups, having more free time and more open schedules due to the school closure can mean more time for part-time work. In case that the work is carried out in essential business sectors (e.g., food industry), remote work possibilities may not be an option. This could effectively result in more frequent driving associated with these groups of people.

An interesting observation was noted by Katrakazas et al. [35], who comparatively studied Greece and the Kingdom of Saudi Arabia. Using Apple mobility reports, they reported "a slight increase in speeds by 6-11\%" but also a significant rise in risky driving behavior, including harsh acceleration, harsh braking, and mobile phone use. According to the authors, this type of behavior can be directly attributed to the effect of reduced traffic density in the study areas. From a policy-making perspective, this effect should be tackled appropriately. In fact, higher levels of willingness to speeding, as an example, generally mean less safe driving and a higher risk of collision. Therefore, we can briefly conclude that the reduction in traffic density to the COVID-19 countermeasures brings not only positives but also a number of new issues and research challenges.

\section{Methodology}

The input data for the analysis, comprising traffic measurements in selected Czech roads, were provided by the Road and Motorway Directorate of the Czech Republic. These data reflect the real traffic flow at a given hour and the measured road segments. The provided traffic data were created by merging various traffic data. In particular, these include FCD, data acquired from traffic detectors, electronic toll systems, CCTVs, and installed induction loops [36]. The resultant merger data are distributed further as real-time traffic information to other organizations, containing values of the currently reached traffic congestion degree, the average current speed, the time necessary for passing the given TMC segment, and also free-flow travel time and speed. These values are provided by the Road and Motorway Directorate of the Czech Republic in minute-resolution at irregular intervals. Road segments, for which real-time traffic information is available, are called TMC segments. There is no further publicly available information about gathering and preprocessing of data. This activity is carried out by the Road and Motorway Directorate of the Czech Republic, as a state-funded organization established by the Ministry of Transport of the Czech Republic, and it provides no further information with respect to this process.

Traffic data collection from the Road and Motorway Directorate of the Czech Republic, involving 20,504 road segments in the Czech Republic, was performed between 7 January and 29 June 2020 . The data cover the measurements from $37,002 \mathrm{~km}$ of roads, which amounts to $66 \%$ of all road segments in the Czech Republic, and in total, there are $176,795,419$ records available. Only roads of local significance (local or purpose-built roads) with a low rate of vehicle passage were excluded. Figure 2 provides a basic description of this data coverage of the Czech Republic. 


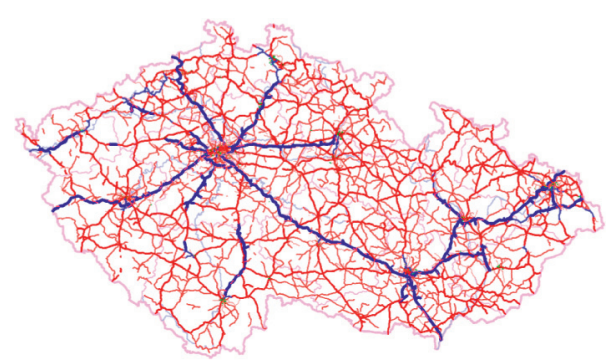

Figure 2: Visualization of TMC segments covering all main roads displayed on the map of the Czech Republic. Blue highlights motorways, red highlights major roads, and pink highlights $1^{\text {st }}-3^{\text {rd }}$ class roads. All road types in the Czech Republic and their equivalents according to OpenStreetMap can be found in Section 3.2.

The frequency of measurements varies significantly across the individual segments. Information about the achieved speed from a single measurement in a given segment will be highly affected by individual factors, such as the type of vehicle, nature of load, and individual skills of the driver. That is why the authors decided to perform aggregation of all measurements per one hour from one segment into a single record. This record keeps information concerning the average value of achieved speeds in this specific hour and also concerning the range of speeds per given hour (the minimum and maximum measured speed). At the same time, it stores the number of measurement records that were acquired for this hour. Based on the initial familiarisation with data, data related to the very low traffic at night were excluded. That is why the data concerning the period from 10 p.m. to 5.00 a.m. are excluded from the analysis.

The presented analysis of the impact of the declared state of emergency and the restrictions of movement on traffic works on the assumption that if measurements for a period with a different pattern (such as the state of emergency) are hidden from the prediction model, the model will predict speed for the given period, which will correspond to a normal situation. Subsequently, we calculated the average (hourly) relative deviation in speed between the predicted speed (standard nonpandemic situation) and the speed measured in the given segment (see Section 4.1).

3.1. Description of Ensemble Prediction Model. Within the research project TH04010350 administered by the Technology Agency of the Czech Republic [37], an ensemble prediction model was created predicting hourly speeds per each individual road segment within the road network of the Czech Republic for the purpose of better navigation (e.g., more accurate arrival time and route optimization with waypoints). The long-term traffic speed ensemble prediction model was presented in [38]. This model is used even in this article for the analysis of the impact of extraordinary measures. For the prediction model learning, the aforementioned traffic data from the period from 7 January to 14 June 2020 were used, excluding the period of the ordered state of emergency and the restriction of movement plus a few extra days (10 March-30 April 2020).
The stated prediction model was validated in terms of traffic prediction for the week from 15 June to 21 June 2020 for all 20,504 road segments. The acquired evaluation results are comparable with similar models. Out of all the individual predictions, the mean absolute error (MAE) of this model (across all TMC segments) is $4.67 \mathrm{~km} / \mathrm{h}$ with a standard deviation of $1.642 \mathrm{~km} / \mathrm{h}$. For comparison, the authors also provide the results acquired through models of similar focus. For instance, the multiscale spatiotemporal feature learning network (MSTFLN) reached the average MAE of $5.72 \mathrm{~km} / \mathrm{h}$ per given hour; the CNN-LSTM model has the MAE of $5.4 \mathrm{~km} / \mathrm{h}$ for hourly prediction $[39,40]$. Based on this information, the ensemble prediction model itself can be considered suitable for the prediction of normal traffic conditions for the period of the state of emergency with the adopted restriction of movement in the Czech Republic.

The ensemble prediction model [38] consists of three submodels introduced in more detail in Sections 3.1.1-3.1.3. This comprises a case-based reasoning (CBR) submodel, a linear regression (LinR) submodel, and a fallback submodel. The main input of the ensemble prediction model is the hour and TMC segment identifier (Tmcld) for which the prediction is to be calculated. The main model output is the expected speed.

3.1.1. CBR Submodel. This technique is based on the selection of a subset of representative cases from the available history. As for the prediction of expected speed, the types of day and hour were identified as the two most important factors. From the available history of hourly aggregated values for the given TMC segment, such records are selected that concern the same hour for which the prediction is to be issued, and these are also the hours of the same type of day.

When selecting the same type of day, the model distinguishes between workdays and days off. As for workdays, it distinguishes each day between Monday and Friday; as for the days off, it considers Saturday and Sunday. For the less frequent types of the day (Friday or Monday bank holiday), the selection is made of a similar type of day, so that it is possible to find a sufficient number of examples in the history.

Prediction of speed upon passing a TMC segment is, subsequently, calculated as the average value of hourly 
speeds out of all representative cases in the currently selected subset of historical data:

$$
P_{\mathrm{CBR}} \text { (hour) }=\frac{\sum_{i=1}^{n_{h}} S_{i} \times \Phi(i, \text { hour })}{\sum_{i=1}^{n_{h}} \Phi(i, \text { hour })}
$$

where

(i) $P_{\mathrm{CBR}}($ hour $)=$ prediction of average speed for a given segment at the "hour" (ii) $n_{h}=$ number of records in history for the given TMC segment

(iii) $S_{i}=$ average hourly speed from an $i$-th record in the history

(iv) $\Phi(i$, hour $)=$ Boolean function of similarity providing values of $\{0,1\}$ depending on whether the $i$-th record in the history has the same hour and the day of the week as the "hour" the prediction is currently made for

$$
\Phi(i, \text { hour })=\left\langle\begin{array}{l}
1 \Longleftrightarrow\left(\operatorname{hour}\left(S_{i}\right)=\operatorname{hour}\right) \wedge\left(\operatorname{dayofweek}\left(S_{i}\right)=\operatorname{dayofweek}(\text { hour })\right) \\
0 \Longleftrightarrow \text { otherwise, }
\end{array}\right.
$$

(v) Hour $\left(S_{i}\right)=$ hour for which the speed $S_{i}$ was measured

(vi) Dayofweek $\left(S_{i}\right)=$ type of day of the week for which the speed $S_{i}$ was measured

(vii) Dayofweek (hour) = function providing the type of the day in the week for the hour for which the prediction is being calculated

3.1.2. LinR Submodel. This model attempts to include influences of other factors into prediction. Provided that there is a vast subset of representative cases available for a given hour in a given segment (see the similarity function $\Phi(i$, hour) above), we use multiple linear regression with vector $x_{i}$ of explanatory variables and dependant variable $y_{i}$.

$$
\forall i=1 \ldots n_{h}^{*}: \vec{\alpha} \cdot \vec{x}_{i}+\varepsilon_{i}=y_{i},
$$

where

(i) $n_{h}^{*}=$ number of records from history for which it applies $\Phi(i$, hour $)=1$ (see above)

(ii) $\vec{x}_{i}=\left[1\right.$, Trend $_{i}, \sin \left(\right.$ Season $\left._{i}\right), \cos \left(\right.$ Season $\left._{i}\right)$, Sun $\left._{i}\right]$

(iii) $\mathrm{Trend}_{i}=$ order number of the day (calculated as of 1 January 2020)

(iv) Season $_{i}=2 \times \pi \times$ DayOfYearIndex $\left(S_{i}\right) / 365$, the standardised order number of the day in the year

(v) $\operatorname{Sun}_{i}=$ fuzzy function providing the coefficient of the sun-above-the-horizon period for the hour of $i$ th record as follows:

$\langle 0 ; 1\rangle$ for the period of 60 minutes before and upon sunrise as at $\mathrm{HH}: 30$

$\langle 0 ; 1\rangle$ for the period of 60 minutes before and upon sunset as at $\mathrm{HH}: 30$

Otherwise, 0 if the sun is below the horizon and 1 if the sun is above the horizon for the entire hour

(vi) $y_{i}=S_{i} /$ FreeFlowSpeed is the relative average hourly speed. Dividing by the value of FreeFlowSpeed does not affect the prediction quality; it only ensures that the calculated regression coefficients are mutually comparable among the individual
TMC segments; definition of FreeFlowSpeed can be found in Section 3.2

(vii) $\varepsilon_{i}$ is the random file (prediction error)

The vector on the left side is currently created by the following components: mean value, trend, season, and information on whether the sun is above the horizon. The last component solely applies to hours where there is a change during the course of the year between the summer and winter solstice; e.g., it will be completely dark outside at 7 p.m. in the winter, yet the sun will be well above the horizon in the summer. As opposed to that, at noons and midnights, this vector component would contain only the same values and is thus eliminated automatically.

After that, we tried to find a vector of regression coefficients $\varepsilon_{i}$ to minimize the sum of squares of random noise $\varepsilon_{i}$, using the least-squares estimation method:

$$
\underset{\vec{\alpha}}{\arg \min } \sum_{i=1}^{n_{h}^{*}} \varepsilon_{i}^{2} \longrightarrow 0
$$

Finally, an expected relative speed is computed as a dotproduct of the vector of regression coefficients $\vec{\alpha}$ and vector $\vec{x}_{\text {hour }}$ of explanatory variables for the hour the prediction is made:

$$
P R_{\text {LinR }} \text { (hour) }=\vec{\alpha} \cdot \vec{x}_{\text {hour }}
$$

Linear regression coefficients are computed relative to the FreeFlowSpeed (for vector $\vec{\alpha}$ to be comparable among road segments-see $y_{i}$ above). Therefore, the dot-product must be multiplied by the FreeFlowSpeed to obtain an expected speed in $\mathrm{km} / \mathrm{h}$ :

$$
P_{\text {LinR }}(\text { hour })=P R_{\text {LinR }}(\text { hour }) \times \text { FreeFlowSpeed. }
$$

CBR submodel still remains as a backup model when there are not enough representative cases in the subset and linear regression fails.

3.1.3. Fallback Submodel. Last but not least, we must take into account the situations where the usable history is too short for being sufficient for providing a forecast even for the 
CBR submodel. For certain segments, days of the week, and specific hours, no measured value is available at all (especially at night or at weekends). The only available piece of information for such situations is the FreeFlowSpeed value for the given segment. The prediction will then be provided according to a simple equation:

$$
P_{\text {fallback }}=k_{F} \times \text { FreeFlowSpeed, }
$$

where $k_{F}$ is the correction coefficient. The simplest variant will be that $k_{F}=1.0$. The fallback submodel is used if there are less than three records available in the history or if the records in the history are based on less than 20 records of individual measurements (the number was determined on an experimental basis).

3.2. Exploration of Traffic Data. For the initial analysis, the FreeFlowSpeed data concerning the individual segments were used along with the data on the measured speeds. FreeFlowSpeed is the speed of passage through a given segment under ideal weather conditions without any restrictions arising from a higher traffic density or construction restrictions. To compare various types of road segments, the difference between both speeds, i.e., SpeedDiff $(\mathrm{km} / \mathrm{h})$, or more precisely, the relative speed difference SpeedDiffRel, was calculated from the stated values. It applies that the higher the SpeedDiff value, the slower was the passage through the segment compared to FreeFlowSpeed. It must be taken into account that the speed of passage through the segment is also influenced by other factors other than just the traffic density. However, no other data are available.

Figure 3 illustrates the development of the average hourly SpeedDiffRel (relative deviation from FreeFlowSpeed) for the period from 24 February to 7 June 2020. The thick blue line highlights the average for all the segments. Furthermore, selected types of segments are highlighted in other colours (motorways are highlighted in black, $1^{\text {st }}$ class roads are violet, and residential area roads are green). The selected segment types are explored in more detail in Section 4.2 .

The state of emergency was declared on Thursday, 12 March, and as of Friday, 13 March 2020, the restriction of movement was to have an impact on the achieved speeds on the roads. Particularly, due to the low traffic density, speeds achieved nearly in all road segments were with a lower deviation from FreeFlowSpeed. However, a significant impact seems to become evident only from Monday, 16 March 2020, with a certain decrease recorded already at the weekend.

During the following three weeks (16 March-6 April 2020), the traffic decline became considerable and the slowdown due to traffic density was substantially lower compared to a normal situation (period highlighted as the dark grey area). Approximately as of 6 April, the traffic started gradually getting back to normal. The question is to which extent there was an increase in traffic speeds and since when exactly the situation could be called "back to normal before the coronacrisis." The results of the analysis (see Figure 3) imply that despite the state of emergency being terminated only on 17 May 2020, traffic got back to normal already in the week from 27 April 2020. According to Figure 1, it should be mentioned that the numbers of newly identified people infected with COVID-19 after 27 April 2020 got stabilised. The number of infected persons between 27 April and 17 May 2020 did not change significantly.

To add more context, Figure 4 illustrates the number of measurements available for the same period as in Figure 3. Most measurements were performed based on FCD, where the input data are from company fleets, in particular. This is associated with the irregularity of measurements and their frequency. It can be concluded from Figure 4 that the number of drives realised by company fleets was reduced in the first month of the state of emergency because the frequency of measurements was also reduced. Subsequently, the number of drives went gradually back to normal. A week (from 11 May 2020) before the termination of the state of emergency, the number of drives was higher than the measurements available before declaring the state of emergency.

Based on data exploration, an overview of all road types, for which traffic measurements are available, was selected for a detailed analysis, as presented in Section 4.1. This involves the following road types [and their equivalents according to OpenStreetMap]: motorways [Motorway], major road network [Trunk], first-class to third-class roads $\left[1^{\text {st }}-3^{\text {rd }}\right.$ class road], residential area roads [Residential], service roads [Service], tracks [Track], and other roads [Other]. Out of the aforementioned types, three road types were selected for a separate analysis: motorways, $1^{\text {st }}$ class roads, and residential area roads. The results concerning these three road types are the most interesting ones with the greatest differences (see Section 4.2). In Section 4.3, the authors focused on the average hourly relative deviation in speed in more detail with respect to two-week periods (always starting from Monday):

(i) Period before and after declaring the state of emergency from 9 March to 22 March 2020

(ii) Two-week period from 23 March to 5 April 2020

(iii) Period around Easter from 6 April to 19 April 2020

(iv) Two-week period from 20 April to 3 May 2020

(v) Two-week period from 4 May to 17 May 2020 (termination of state of emergency)

\section{Results}

4.1. Summary Results of Achieved Speeds in the State of Emergency Period. Data illustrated in Figure 5 arise from measurements and prediction (normal situation) of daily average speeds calculated from hourly time series in the period from 24 February to 7 June 2020. The deviation of measured speeds from FreeFlowSpeed for individual days is highlighted in blue, including the measurements from the period of the state of emergency (grey area in Figure 5). The deviation of predicted speed values from FreeFlowSpeed for individual days is highlighted in red. Predicted values are 


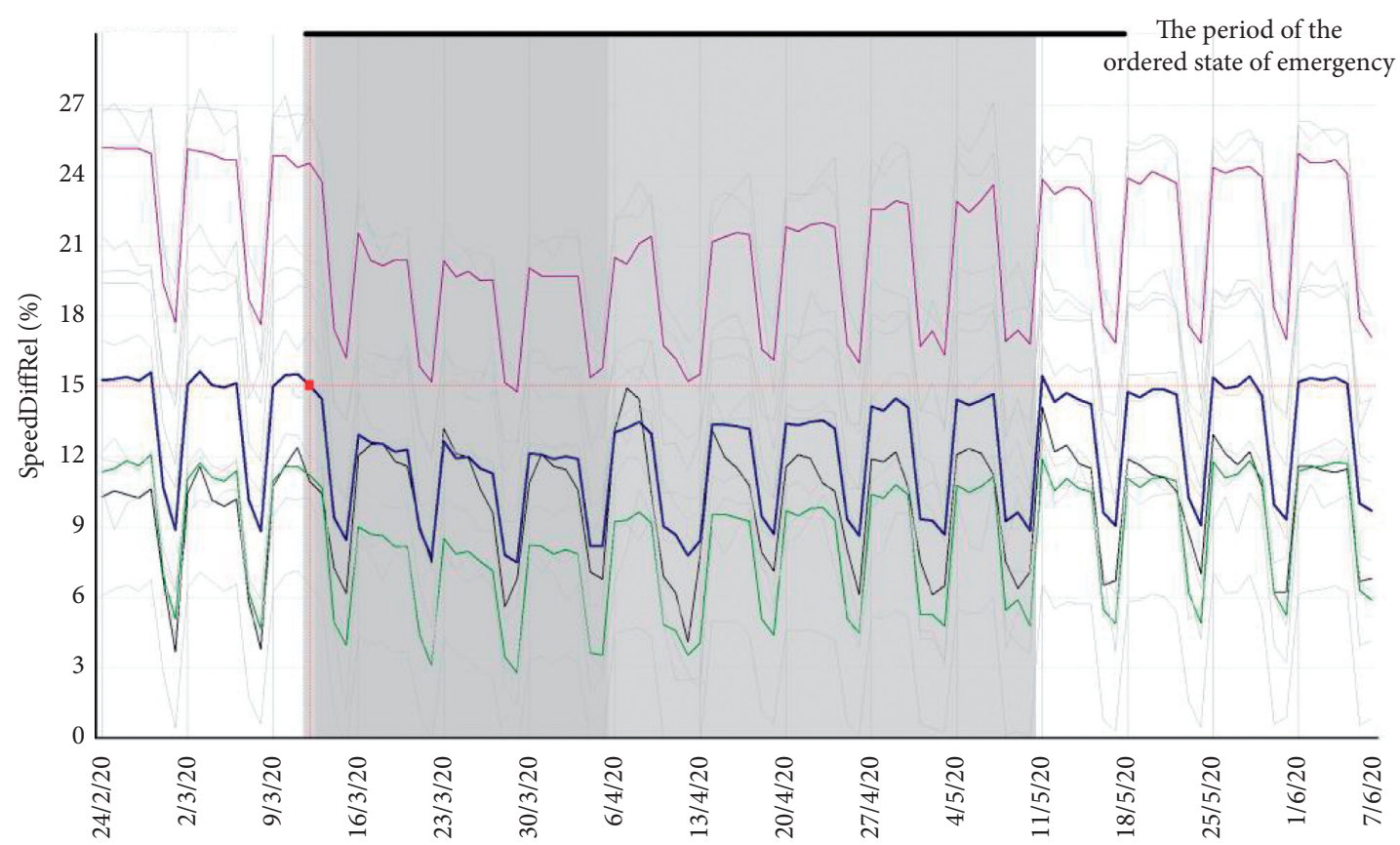

Figure 3: Average hourly relative deviation from FreeFlowSpeed. Motorways are highlighted in black, $1^{\text {st }}$ class roads are violet, and residential area roads are green.

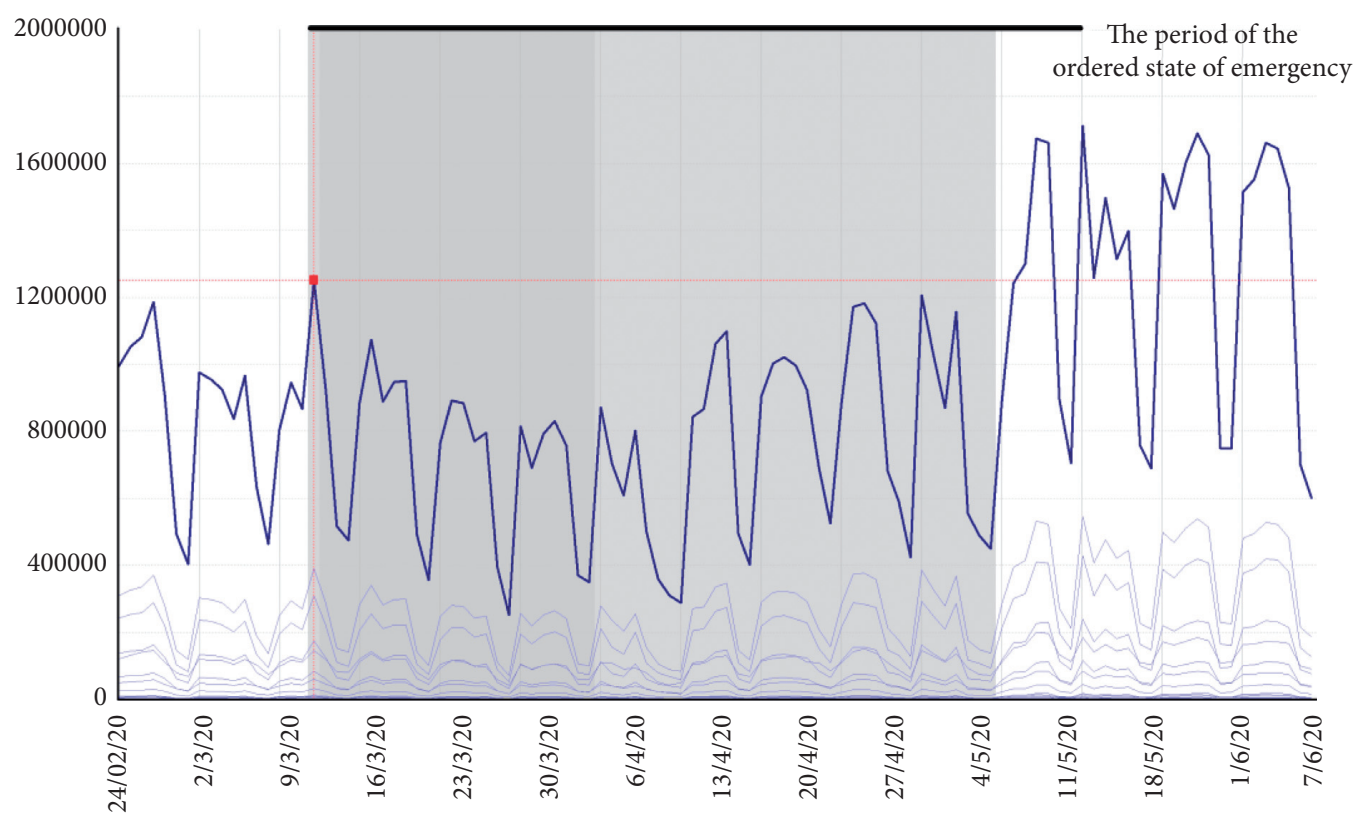

Figure 4: The number of measurements from 24 February to 7 June 2020.

calculated by the ensemble prediction model introduced above. This is thus the prediction of a normal situation. Green curve indicates the prediction error, i.e., the difference in the real and expected values of SpeedDiffRel (in percentage points).

Figure 5 illustrates the decrease of the deviation from FreeFlowSpeed and thus an increase in the traffic (blue) caused by the declaration of the state of emergency and the number of restrictive measures in the Czech Republic, as opposed to the theoretical normal situation predicted by the model only using data not affected by the state of emergency (red), for all roads in the Czech Republic. Therefore, the answer to AQ 1.1 can be provided.

How did traffic speed (and thus traffic density) vary in time during the individual weeks of the state of emergency?

According to Figure 5 and Appendix A, the greatest differences in the measured and predicted SpeedDiffRel were detected during the first three weeks (16 March-6 April 2020) of the state of emergency (dark grey area in 


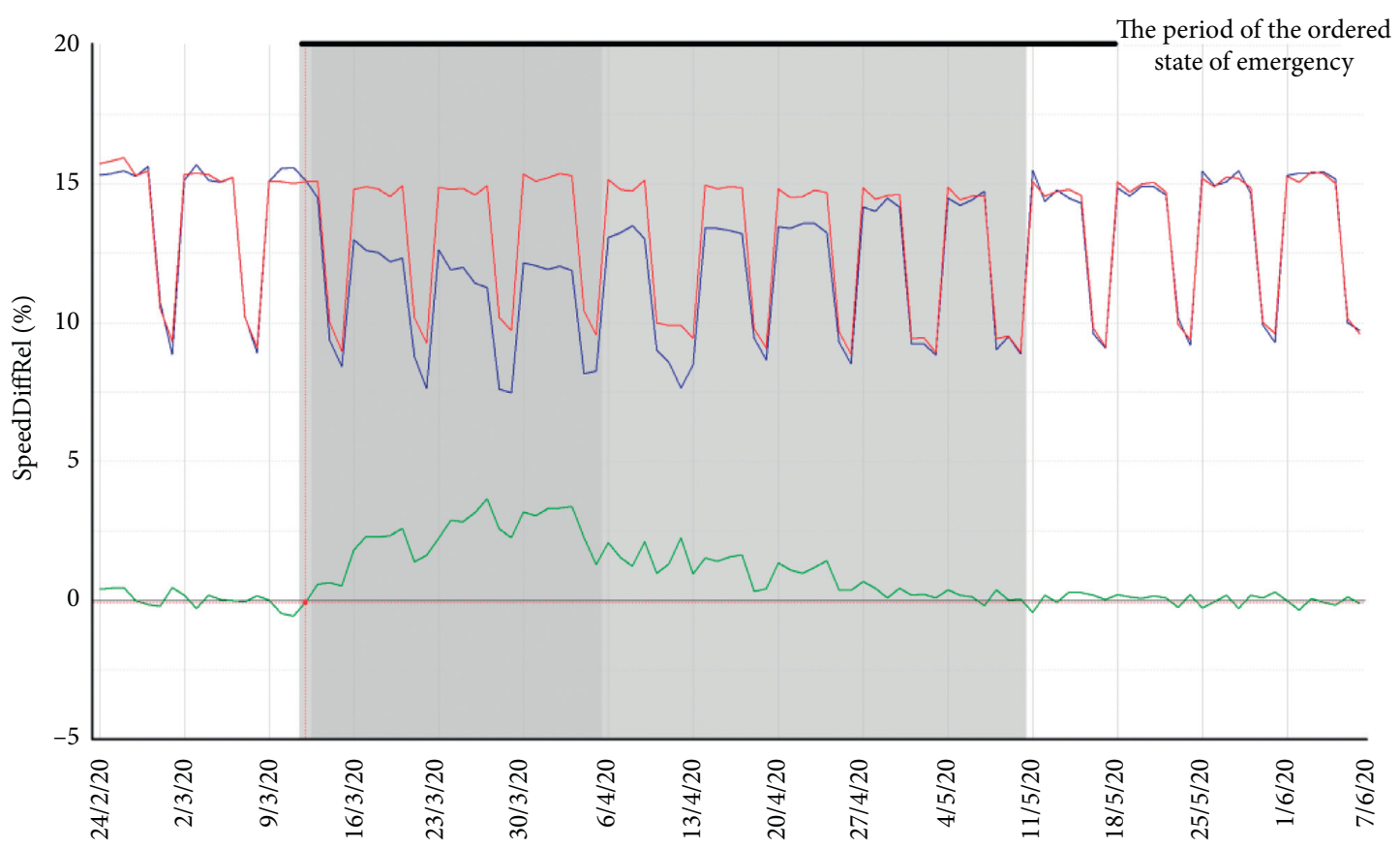

Figure 5: Deviation of the measured (blue) and predicted (red) speed values from FreeFlowSpeed, for all roads in the period from 24 February to 7 June 2020. Green curve indicates the difference in the real and expected values of SpeedDiffRel in percentage points. These are the daily average values.

Figure 5). During this period, drivers reached higher speeds, so it can be concluded that the traffic density was lower, which also led to lower traffic congestion. In the period between 6 April and 20 April 2020, the differences between the measured and predicted values of SpeedDiffRel were not as great as in the first weeks upon declaration of the state of emergency, which was associated with the gradual loosening of governmental restrictions as of 6 April 2020 (see Section 2). As of 27 April 2020 until the termination of the state of emergency on 17 May 2020, the traffic situation can be called "normal," at least from this macroperspective. The individual weeks are described in more detail in Section 4.3.

4.2. Achieved Speeds on Selected Road Types. It may be interesting to compare the measured values of traffic speeds in the period of the state of emergency and the prediction of a normal traffic condition for various types of road segments. Similar to Section 4.1, SpeedDiffRel calculated from the deviation of the daily average measured and predicted speeds from FreeFlowSpeed can be used even for this purpose. Furthermore, the authors used the weekly average values stated in Appendix A. As mentioned in the introduction of Section 4, only three types of segments with the most interesting results were used for the analysis. In this section, the answer to AQ 1.2 can be provided.

How did traffic speed (and thus traffic density) vary across the various road types?

The figures provided in Ssections 4.2.1-4.2.3 and Appendix A imply a major difference between the SpeedDiffRel development on motorways during the monitoring period compared to other road types and the summary overview of all roads provided in Section 4.1. The average weekly speed for both weeks from 23 March to 5 April 2020 (see Appendix A) evinced an aggregate change (increase) by $21 \%$ (3 percentage points); as for motorways, the change detected in the first week was solely by $11 \%$ (1 percentage point) and in the second week already by $2 \%$, which can be considered as a normal situation. As opposed to that, the greatest changes in speed are detected with $1^{\text {st }}$ class roads, where the speed changed by $33 \%$ (3 percentage points) in both weeks. Due to the fact that motorways are mainly used for long-distance transport and international transport, it can be assumed that this type of transport, in particular, was not highly impacted by the state of emergency. The only exception to this was the period from 13 March to 25 March 2020 and the period just before Easter, where traffic density increased even more than that in the normal situation. Opposed to that, the state of emergency impacted $1^{\text {st }}$ class roads the most, as the traffic density was reduced significantly in these roads.

Significantly different development was recorded on roads within residential areas, where traffic speed in the period from 23 March to 5 April 2020 increased only by $18 \%$ and $17 \%$, respectively (see Appendix A). However, the return to normal was very slow and de facto lasted until the termination of the state of emergency on 17 May 2020. This implies that the state of emergency (reduction of traffic density) affected public transport the most, as people limited their commuting (e.g., they worked from home). The aforementioned is illustrated by Figure 6. and by Appendix A.

4.2.1. Motorways. According to Figure 7, motorways did not show any reduction of traffic density associated with the state of emergency. In the first weeks following the 


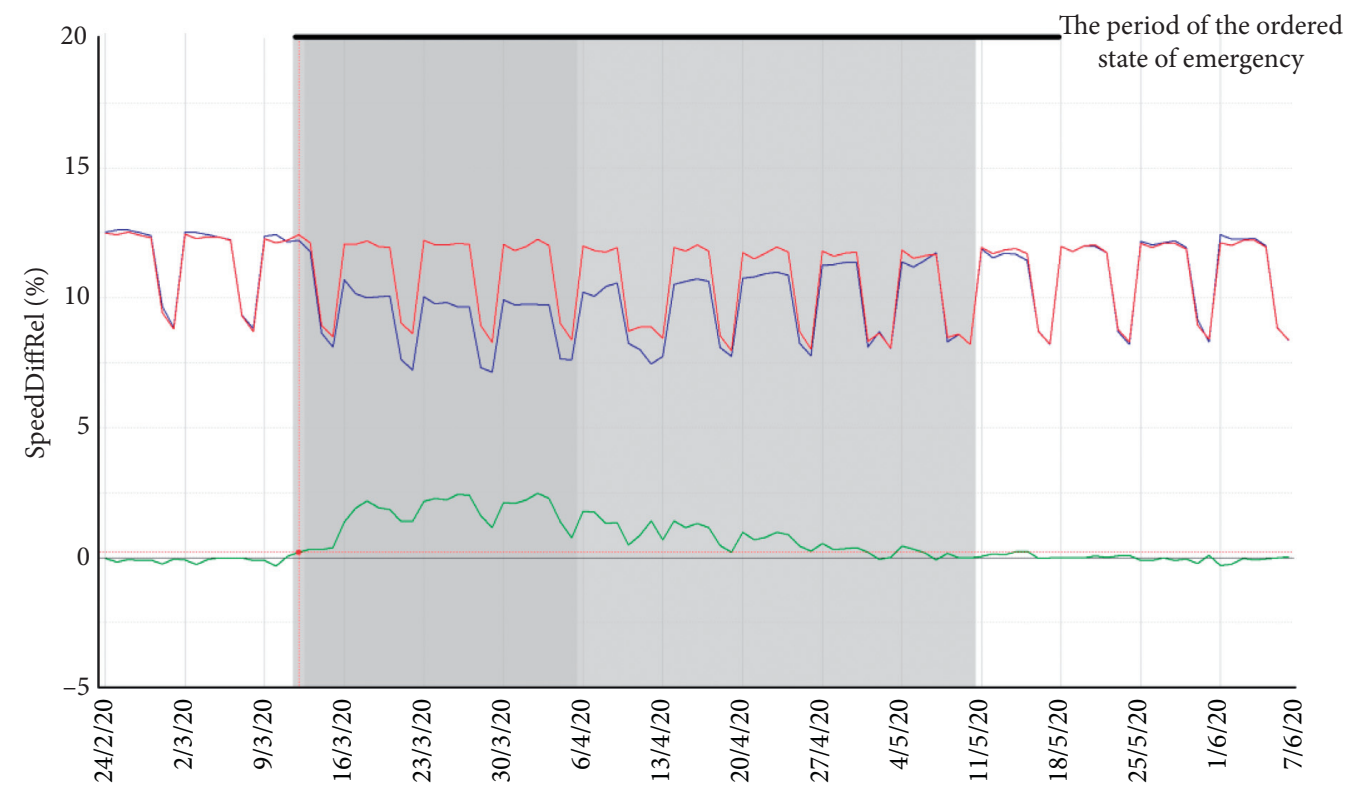

Figure 6: Deviation of the measured and predicted speed values from FreeFlowSpeed for residential area roads in the period from 24 February to 7 June 2020. These are the daily average values.

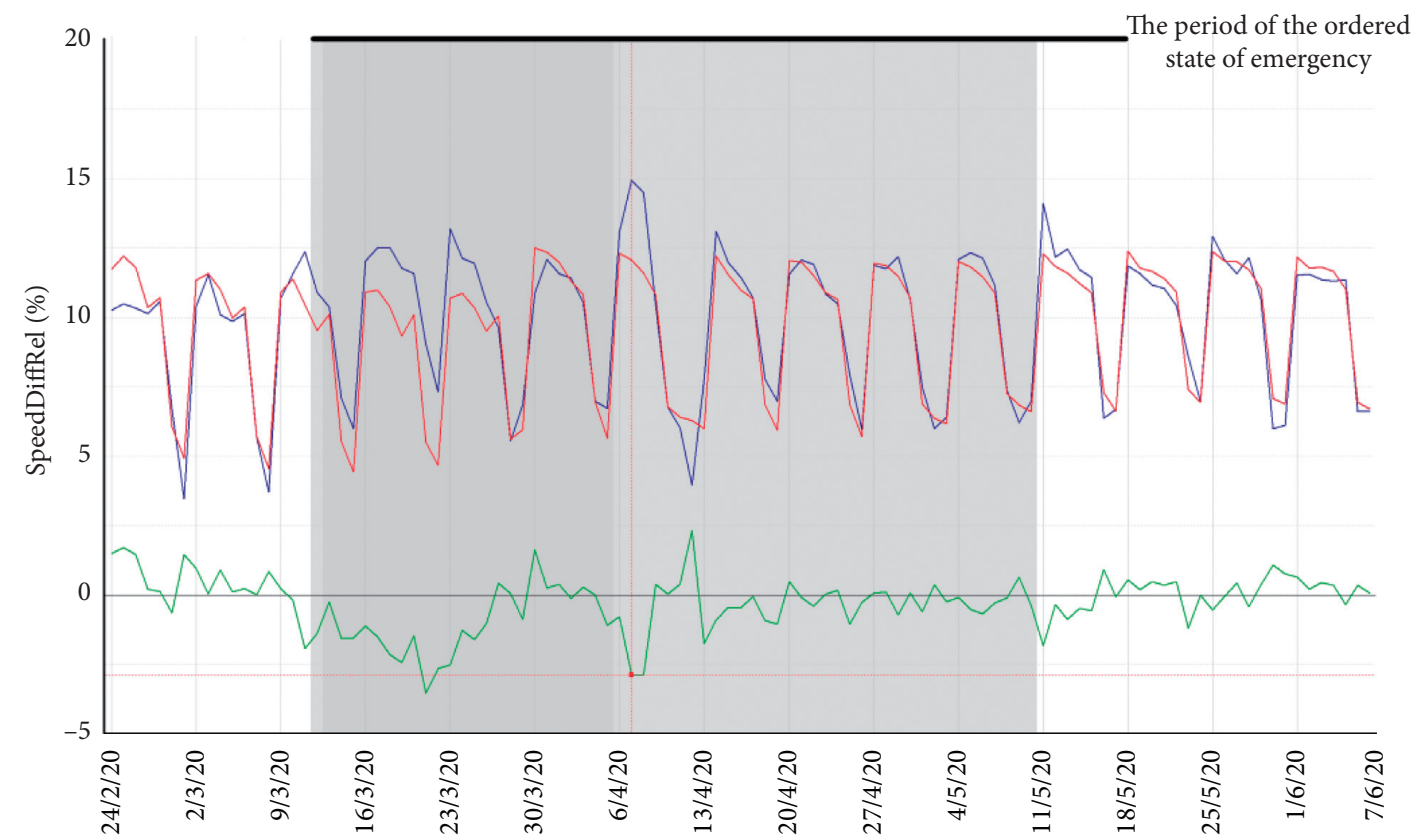

FiguRE 7: Deviation of the measured and predicted speed values from FreeFlowSpeed for motorways in the period from 24 February to 7 June 2020. These are the daily average values.

declaration of the state of emergency, the slowdown of traffic flow was even less significant. Significant speed reduction was recorded even on 7 April 2020 (Tuesday). This may have been due to further loosening of restrictions (see Section 2), where DIY retail stores, bicycle repair shops, homeware stores, and some other types of stores were excluded from the sales prohibition. People went shopping, which they could not have done earlier due to the closure of these types of stores. At the same time, people were allowed to leave their homes for the upcoming Easter.
4.2.2. $1^{\text {st }}$ Class Roads. Figure 8 clearly implies the improvement of the achieved speeds compared to the model prediction, especially in the first three whole weeks upon the declaration of the state of emergency and the strict restriction of movement (16 March-6 April 2020). In the week from 6 April 2020, upon the first cases of loosening of the restrictions associated with the state of emergency, traffic speed gradually slowed down, most likely due to the higher traffic density. In the week from 27 April 2020, the speed was nearly on the level predicted by the ensemble prediction 


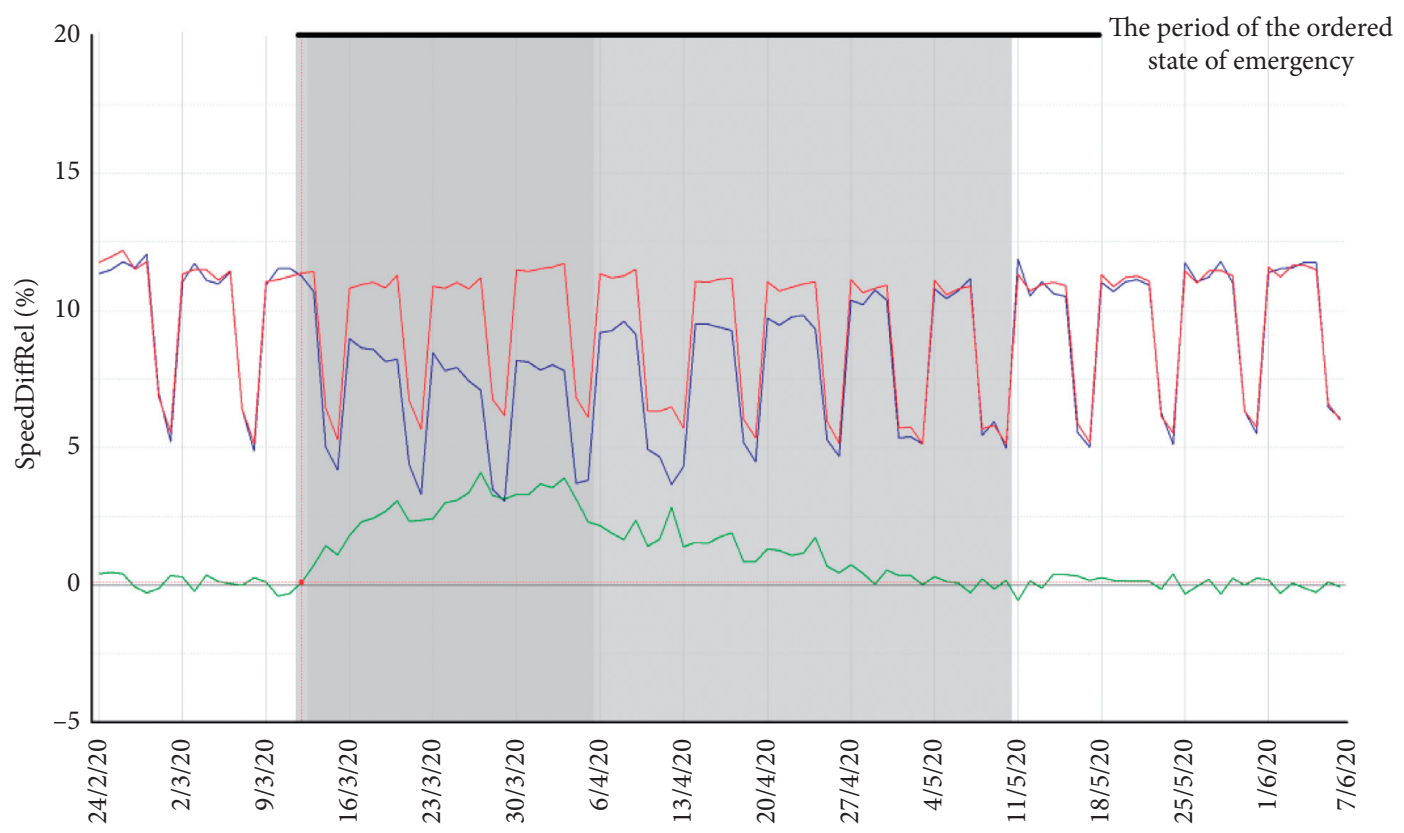

Figure 8: Deviation of the measured and predicted speed values from FreeFlowSpeed for $1^{\text {st }}$ class roads in the period from 24 February to 7 June 2020. These are the daily average values.

model as the normal situation. Similar development can be observed in $2^{\text {nd }}-3^{\text {rd }}$ class roads.

4.2.3. Residential Area Roads. As expected, residential area roads were affected the most, as the return to normal situation also took the longest there. The situation went back to normal only with the termination of the state of emergency after 17 May 2020, as indicated by Figure 6 (see also Appendix A).

4.3. Detailed Analysis of Achieved Speeds in the State of Emergency Period. Figures 9-13 show the curve for SpeedDiffRel in hourly resolution (as opposed to Figure 5, where daily average values are provided), excluding the nighttime. Each figure represents a two-week period, always starting on Monday. Once again, red highlights signify the deviation of prediction speed from FreeFlowSpeed, which was acquired by the ensemble prediction model, i.e., the value expected under a "normal situation." Blue highlights signify the deviation of the measured speed values from FreeFlowSpeed.

As illustrated in Figure 9, on Thursday, 12 March 2020, i.e., on the date when the state of emergency was declared, the impact on achieved speeds was not significant. In fact, there was a slight slowdown. On Friday, 13 March 2020, the achieved speeds basically complied with the values provided by the prediction model. Only a slighter difference was evident at the weekend; however, differences between the actual values (blue: state of emergency) and the prediction of the normal situation (red) were significant from Monday, 16 March 2020.

The declaration of the state of emergency was followed by further restrictions being adopted in fast succession. The most important restrictions included: prohibition of retail sales (except for groceries) and of restaurant operation (as of 14 March 2020), closure of state borders, prohibition of free movement of persons, local quarantine order (as of 16 March 2020), and obligation to wear face masks outside (as of 19 March 2020).

Figure 10 indicates the continuous trend, where the difference between expected and real SpeedDiffRel increased compared to the previous week. In these two weeks, the highest increase of achieved speeds was detected on Czech roads (see Appendix A). The scope of the restrictive measures was the strictest in this period, see Section 2.

Based on Figure 11 (hourly average values of SpeedDiffRel), Figure 5 (daily average values of SpeedDiffRel), and data from Appendix A (weekly average values of SpeedDiffRel), the answer to AQ 1.3 can be provided.

What was traffic development like during Easter (10-13 April 2020 inclusive)?

From the perspective of weekly values of SpeedDiffRel, a slowdown in traffic was still significant. However, when taking into consideration the total overview across all road types, there is still a relative speed difference of 13\% (1.65 percentage points) compared to the normal situation. According to the daily values of SpeedDiffRel, it can be stated that the traffic returned partially back to the normal situation around the Easter period. This may have been 


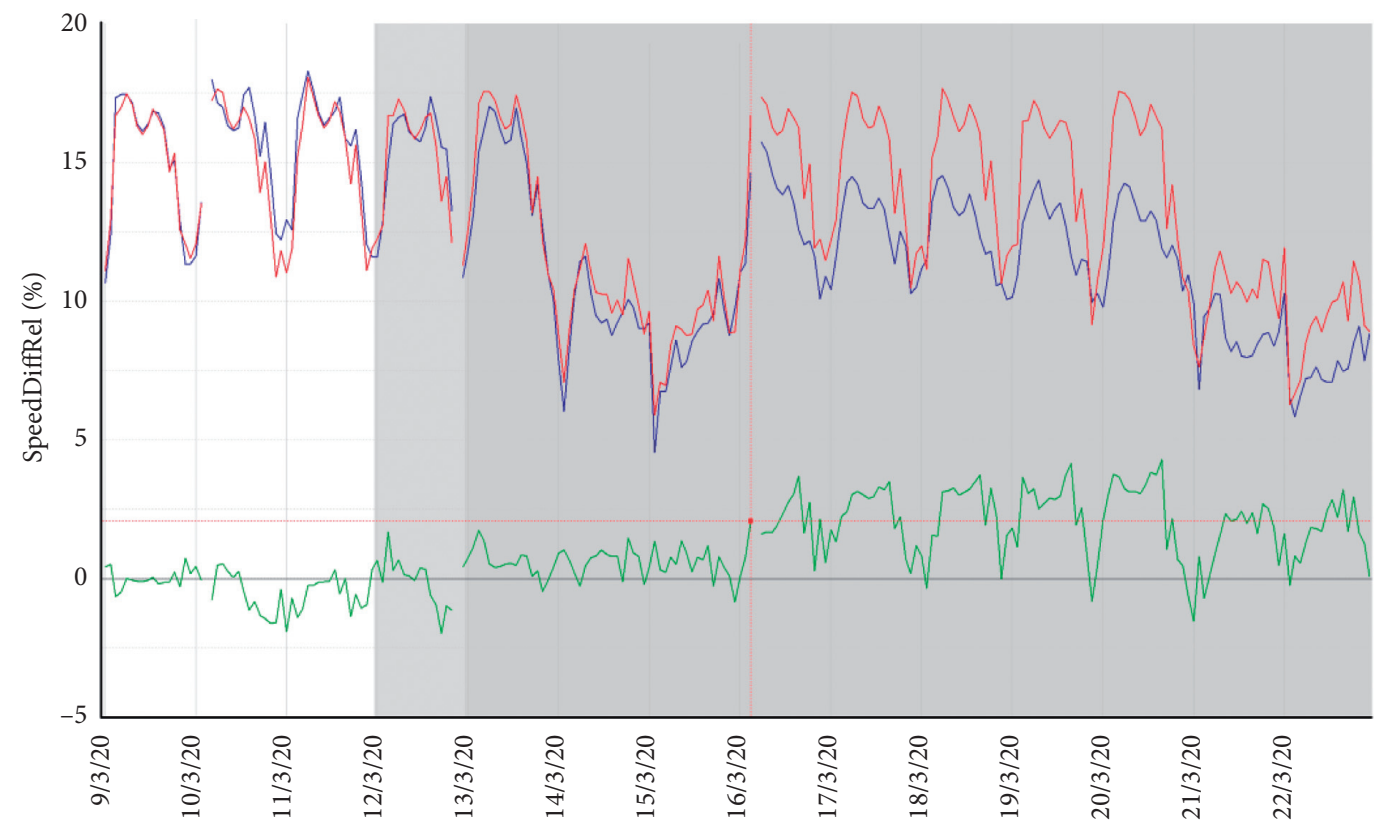

Figure 9: Period before and after declaring the state of emergency from 9 March to 22 March 2020. SpeedDiffRel in percentage points by hours.

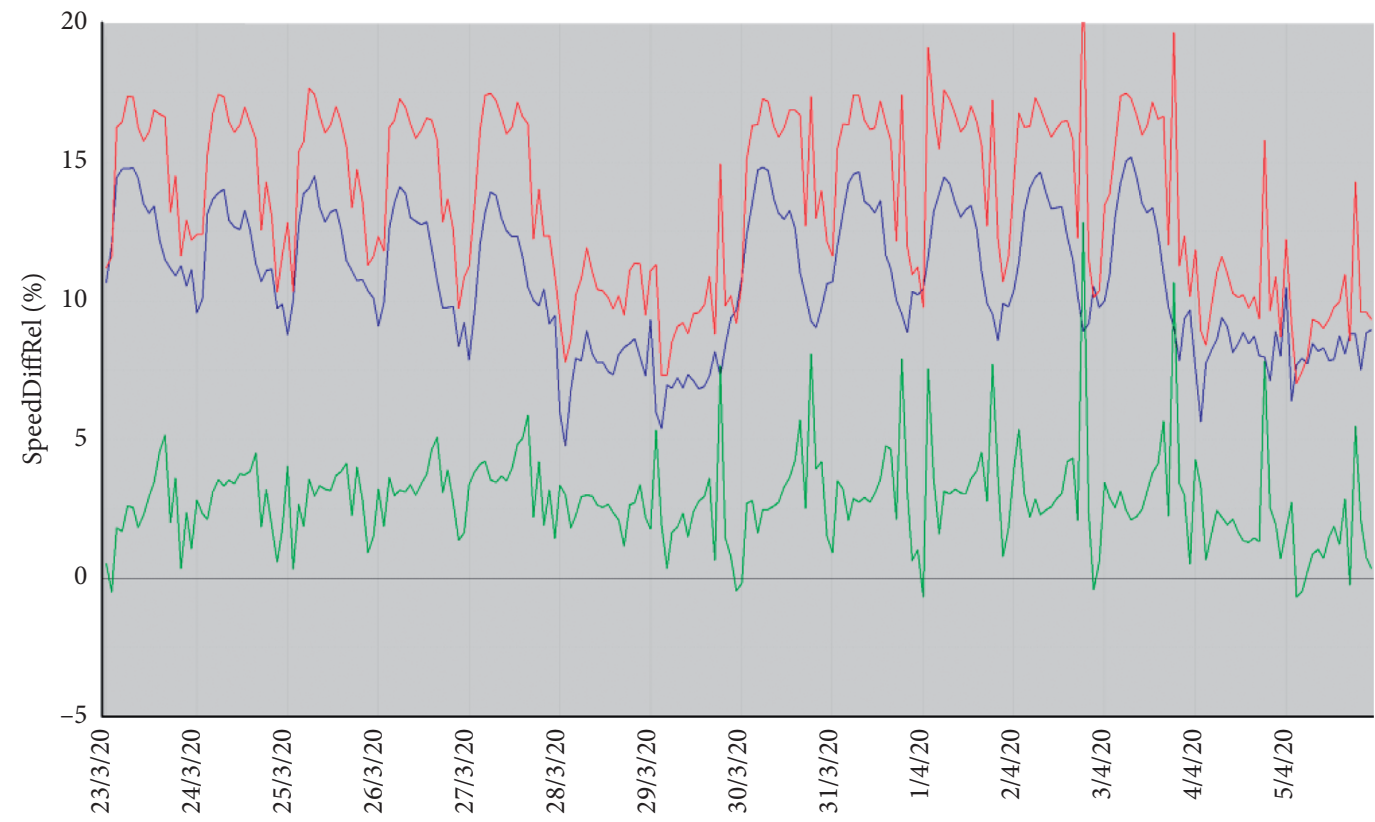

FIgURE 10: Two-week period from 23 March to 5 April 2020. SpeedDiffRel in percentage points by hours.

caused by people travelling for Easter (most likely to their cottages), which also increased the achieved speeds in roads to an ordinary level for holidays. Interestingly, 12 April 2020 (Sunday) was an exception to this, as it was recorded inaccurately by the prediction model due to the lack of representative cases for a holiday where there is a holiday even before and after such a day. People came back from the Easter holidays only on Monday, 13 April 2020, which was evident due to a more significant slowdown of traffic. 


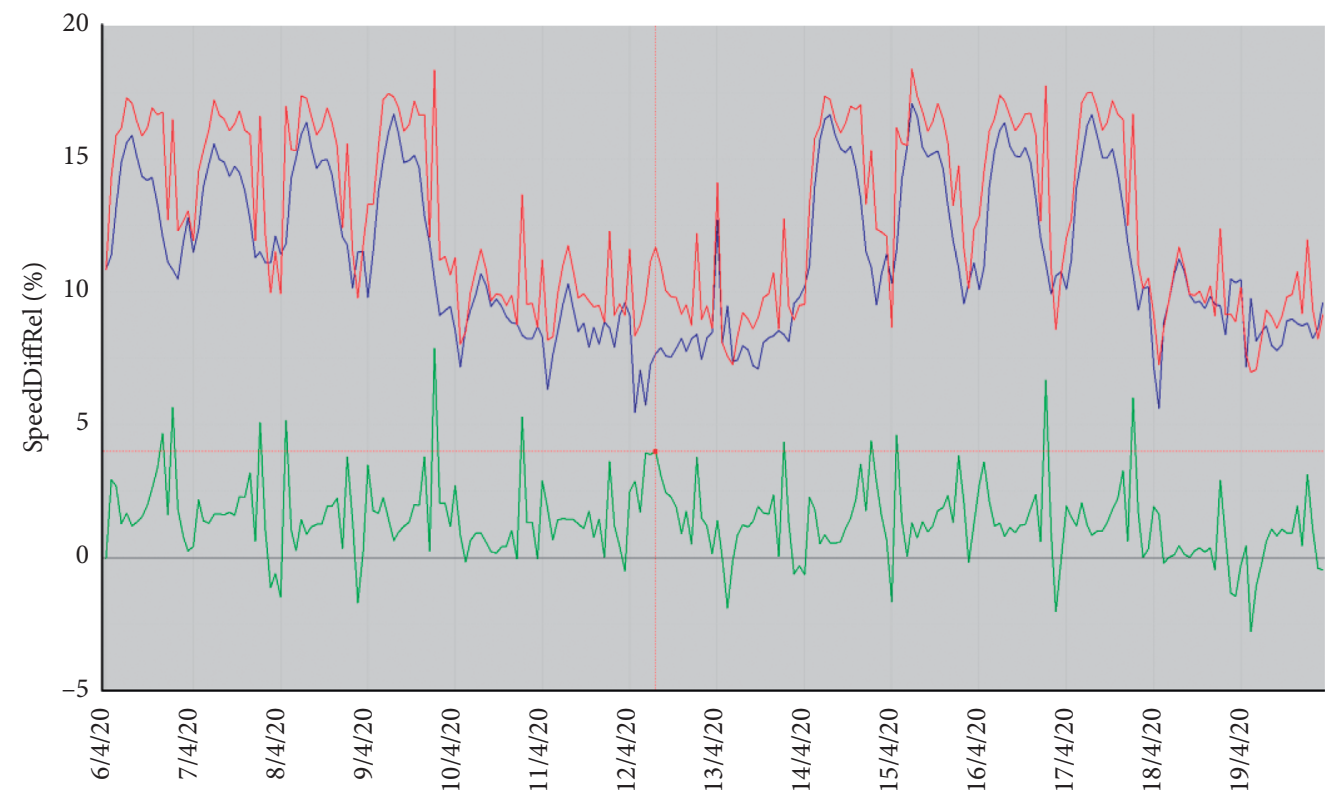

Figure 11: Period around Easter from 6 April 2020 to 19 April 2020. SpeedDiffRel in percentage points by hours.

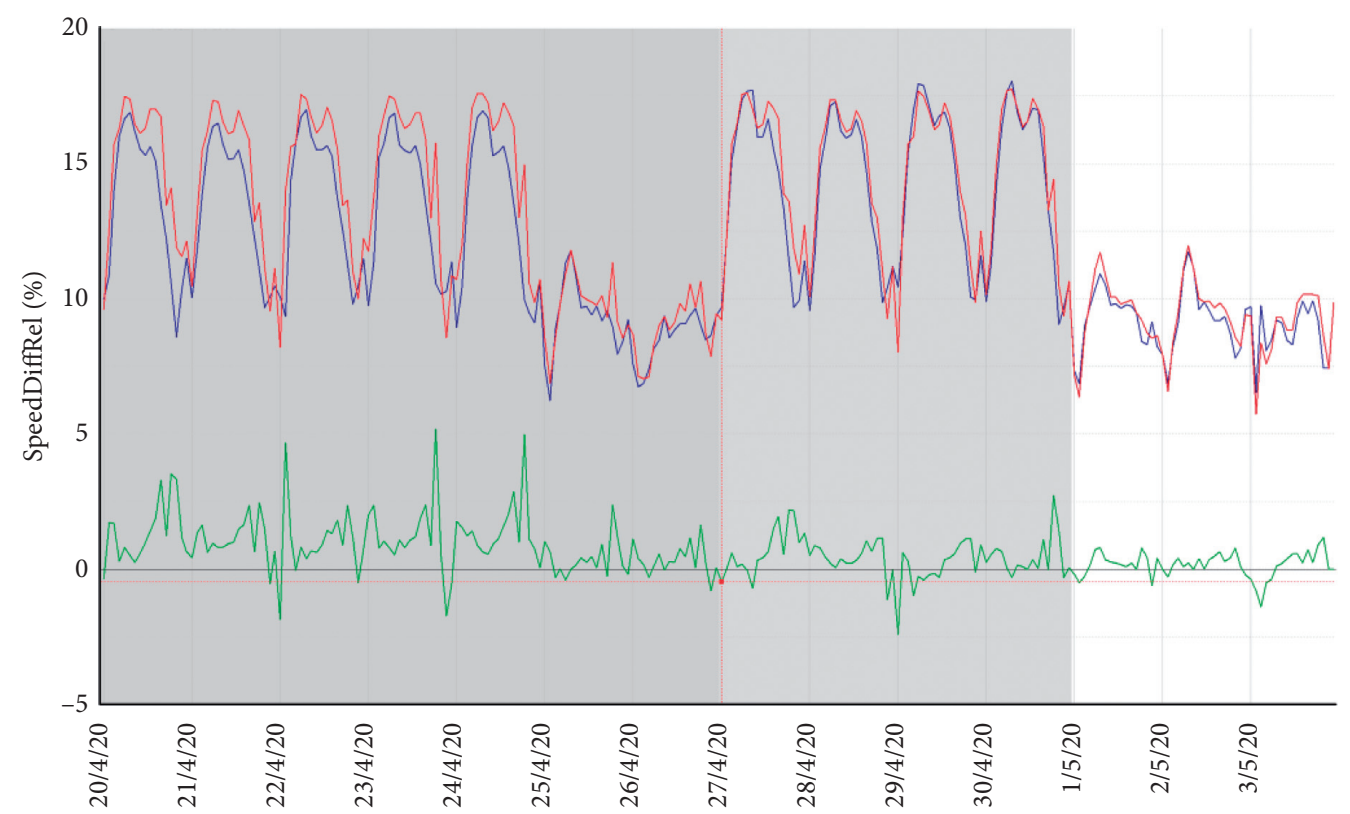

Figure 12: Two-week period from 20 April to 3 May 2020. SpeedDiffRel in percentage points by hours.

As of 7 April 2020, governmental restrictions were being loosened gradually; DIY retail stores and building supply stores were excluded from the prohibition as of 9 April 2020. Furthermore, outside sports venues were reopened as of 7 April 2020.

In the period illustrated in Figure 12, a gradual return to normal traffic conditions can be noticed. On 27 April 2020, the aforementioned governmental restrictions were being loosened gradually; stores of up to $2,500 \mathrm{~m}^{2}$ and restaurant patios were reopened.

Figure 13 illustrates normal traffic conditions despite the fact that the state of emergency was only terminated on 17 May 2020. Nevertheless, the gradual loosening of governmental restrictions as of 7 April 2020 and the reopening of large stores led to the return to normal traffic conditions.

\section{Discussion and Conclusions}

5.1. Main Findings. This article provides an overview of the impact of the COVID-19 antiepidemic measures on road traffic in the Czech Republic. The presented analysis uses unique traffic data, which were measured on the different types of roads, reflecting the situation in the entire territory of the Czech Republic. Overall, the article demonstrates that the declaration of the state of emergency and the restriction 


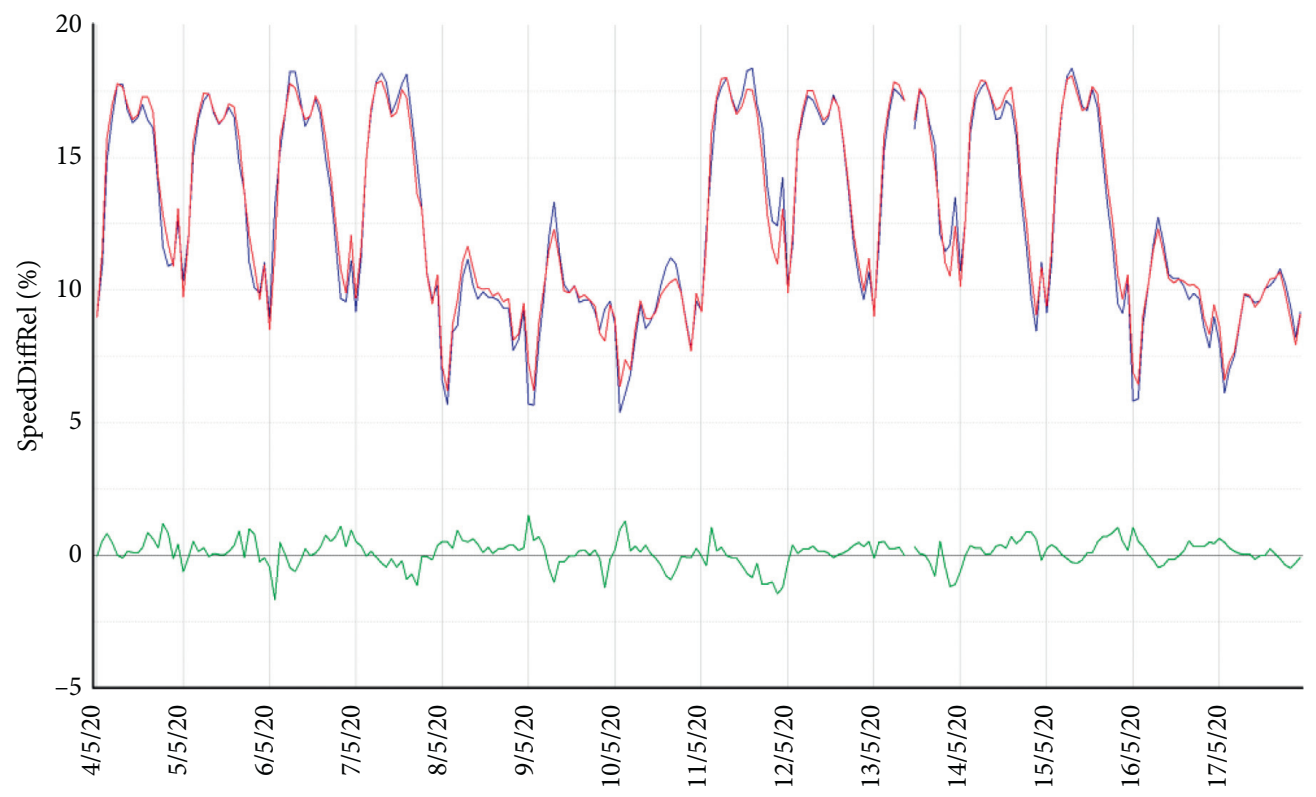

Figure 13: Two-week period from 4 April to 17 May 2020. SpeedDiffRel in percentage points by hours.

of movement initially had a significant impact on the increase of achieved speeds in most road segments in the Czech Republic.

In that sense, the key finding is that the first three weeks (16 March-6 April 2020) after the declaration of the state of emergency represented the period with a significant drop in traffic. Then, traffic intensity changed. In the coming weeks (7 April 2020-27 April 2020), the traffic intensity gradually returned to the previous volume (i.e., prepandemic), with slight deviations depending on the various types of road segments. Considering motorways, a different pattern was observed. During the first week of the state of emergency (16 March-22 March 2021), a significant drop in traffic was noticed. From 23 March to 27 April 2020, in contrast with other road types, no significant impact related to the state of emergency was evident (Appendix A). This pattern might be due to the distinct characteristic of long-distance transport and international transport, typically carried through motorways.

An important milestone in the analyzed period was the Easter holiday (Friday 10-Monday 13 April 2020). Easter is the second most important holiday in the Czech Republic, with a lot of annual leaves usually taken during this period. The results show that the traffic returned partially back to the prepandemic state around the Easter period. This was possibly caused by people travelling for Easter (most likely to visit relatives or spend free time at their cottages), which also resulted in decreasing the achieved speeds to levels comparable with the prepandemic values common for holidays. For clarity, a coincidence between the Easter holiday and the first considerable loosing of restrictions after 7 April 2020 should be noted. So, the authors propose that both events together influenced traffic intensity and its gradual return towards the prepandemic values.

Further, the results show that on most road types, traffic fully returned to the prepandemic state during the week of
27 April 2020. Interestingly, this happened three weeks prior to the state of emergency was officially terminated by the government. With regard to residential area roads, a different pattern was observed. On these types of roads, traffic returned to the prepandemic state only after 17 May 2020, i.e., three weeks later.

Contrasting the authors' findings with the data from Apple Maps (Figure 1), the following thesis may be articulated. Both data sources show a similar trend. The main difference between both data sources seems to be the moment when one can talk about a return to the previous state of "normality" (i.e., prepandemic). While the authors' results indicate that the period after 27 April 2020 can be viewed as a complete return to normality (Figure 5), Apple Maps data (Figure 1) suggest that it was only the period after 6 May 2020 , i.e., a week later. This difference between the authors' results and Apple results may be due to different types of source data used, varying approaches to data collection, and the limited amount of data from the Czech Republic collected by Apple overall (see Section 2.1).

In the next section, the above findings are interpreted from a perspective that highlights the importance of national culture and people's behavior.

5.2. National Context and Travel Behavior. Broadly, the development of the COVID-19 pandemic was quite specific in the Czech Republic. Being concerned about the trend of spreading the COVID-19 infection in other European countries, the Czech government adopted the first antiepidemic measures as of 12 March 2020, with fewer than 100 infected persons in the territory. Within a few days, the number and scope of restrictive measures even increased. However, it should be noted that the level of restrictions adopted in the Czech Republic was not as severe as in many other European countries during the given periods. 
TABle 2: Basic overview for all road types and three selected road types: motorways, $1^{\text {st }}$ class roads, and residential area roads.

\begin{tabular}{|c|c|c|c|c|c|c|c|c|c|}
\hline State & Week & $\begin{array}{l}\text { All road } \\
\text { types* }\end{array}$ & $\begin{array}{l}\text { All road } \\
\text { types }^{+}\end{array}$ & Motorways* & Motorways $^{+}$ & $\begin{array}{l}1^{\text {st }} \text { class } \\
\text { roads* }\end{array}$ & $\begin{array}{l}1^{\text {st }} \text { class } \\
\text { roads }^{+}\end{array}$ & $\begin{array}{c}\text { Residential area } \\
\text { roads* }\end{array}$ & $\begin{array}{c}\text { Residential area } \\
\text { roads }^{+}\end{array}$ \\
\hline NS & $\begin{array}{c}24 / 2 / 2020-1 / \\
3 / 2020\end{array}$ & 0.21 & $1.49 \%$ & 0.83 & $8.59 \%$ & 0.17 & $1.66 \%$ & 0.2 & $0.89 \%$ \\
\hline NS & $\begin{array}{c}2 / 3 / 2020-8 / \\
3 / 2020\end{array}$ & 0.04 & $0.27 \%$ & 0.44 & $4.91 \%$ & 0.12 & $1.27 \%$ & 0.16 & $0.71 \%$ \\
\hline $\begin{array}{l}\text { NS and ES } \\
\text { from } 12 / 3\end{array}$ & $\begin{array}{c}9 / 3 / 2020-15 / \\
3 / 2020 \\
16 / 3 /\end{array}$ & 0.1 & $0.79 \%$ & 0.93 & $10.68 \%$ & 0.41 & $4.26 \%$ & 0.25 & $1.16 \%$ \\
\hline ES & $\begin{array}{c}2020-22 / 3 / \\
2020 \\
23 / 3 /\end{array}$ & 2.04 & $15.43 \%$ & 2.11 & $24.16 \%$ & 2.42 & $25.37 \%$ & 3.43 & $15.53 \%$ \\
\hline ES & $\begin{array}{c}2020-29 / 3 / \\
2020\end{array}$ & 2.81 & $20.95 \%$ & 0.97 & $10.79 \%$ & 3.2 & $33.09 \%$ & 4.08 & $18.4 \%$ \\
\hline ES & $\begin{array}{c}30 / 3 / 2020-5 / \\
4 / 2020\end{array}$ & 2.84 & $20.61 \%$ & 0.2 & $1.91 \%$ & 3.31 & $32.79 \%$ & 3.81 & $17.19 \%$ \\
\hline ES & $\begin{array}{c}6 / 4 / 2020-12 / \\
4 / 2020 \\
13 / 4 /\end{array}$ & 1.65 & $12.88 \%$ & 0.49 & $5.14 \%$ & 2 & $21.7 \%$ & 2.58 & $12.18 \%$ \\
\hline ES & $\begin{array}{c}2020-19 / 4 / \\
2020 \\
20 / 4 /\end{array}$ & 1.13 & $9.03 \%$ & 0.79 & $8.6 \%$ & 1.41 & $16 \%$ & 1.84 & $8.87 \%$ \\
\hline ES & $\begin{array}{c}2020-26 / 4 / \\
2020\end{array}$ & 0.98 & $7.43 \%$ & 0.16 & $1.6 \%$ & 1.1 & $11.67 \%$ & 1.44 & $6.66 \%$ \\
\hline ES & $\begin{array}{c}27 / 4 / 2020-3 / \\
5 / 2020\end{array}$ & 0.31 & $2.54 \%$ & 0.13 & $1.38 \%$ & 0.36 & $4.15 \%$ & 0.5 & $2.45 \%$ \\
\hline ES & $\begin{array}{c}4 / 5 / 2020-10 / \\
5 / 2020 \\
11 / 5 /\end{array}$ & 0.14 & $1.15 \%$ & 0.2 & $2.08 \%$ & 0.07 & $0.81 \%$ & 0.3 & $1.48 \%$ \\
\hline ES & $\begin{array}{c}2020-17 / 5 / \\
2020 \\
18 / 5 /\end{array}$ & 0.08 & $0.61 \%$ & 0.45 & $4.44 \%$ & 0.12 & $1.25 \%$ & 0.23 & $1.08 \%$ \\
\hline NS & $\begin{array}{c}2020-24 / 5 / \\
2020 \\
25 / 5 /\end{array}$ & 0.1 & $0.71 \%$ & 0.12 & $1.19 \%$ & 0.16 & $1.68 \%$ & 0.07 & $0.31 \%$ \\
\hline NS & $\begin{array}{c}2020-31 / 5 / \\
2020\end{array}$ & 0.03 & $0.24 \%$ & 0.24 & $2.27 \%$ & 0.01 & $0.06 \%$ & 0.14 & $0.63 \%$ \\
\hline NS & $\begin{array}{c}1 / 6 / 2020-7 / \\
6 / 2020\end{array}$ & 0.07 & $0.50 \%$ & 0.25 & $2.4 \%$ & 0.05 & $0.46 \%$ & 0.2 & $0.9 \%$ \\
\hline
\end{tabular}

ES: emergency state; NS: normal situation. ${ }^{*}$ Relative speed difference in percentage points. ${ }^{+}$Relative speed difference in percentage points compared to normal situation.

For example, differently from countries such as Italy or Spain [41], inhabitants of the Czech Republic moving around by car or on foot were not subjected to systematic checks regarding the legitimacy of their travel reasons. Therefore, one cannot speak about a complete lockdown comparable with that implemented in the said countries [42]. In fact, the situation in the Czech Republic was quite like the situation in the Netherlands, described previously in the literature as an "intelligent lockdown," a "lighter version of a full lockdown" [20]. In that sense, the Czech and Dutch cases represented quite a liberal approach. Being focused mostly on urging people to limit their travels, the measures still granted them many opportunities to move. For example, leisure in nature has always been possible in the Czech case, even during the initial period of the state of emergency.

Furthermore, due to legislation and cultural differences, it is hard to directly compare such measures with stay-athome orders as implemented in the United States [42], especially when considering the diversity of the latter [43]. Arguably, the Czech measures were more strongly articulated, being both more explicit and, at least during Spring 2020, more impactful than in the United States [42].

The arguments above encourage the authors to speculate that the observed effects were not only due to the de jure (i.e., official and formal) restrictions. The Czech Republic is a central-Europe country with a low number of COVID-19 cases in the observed period (Figure 1). In a geographic sense, the country was distanced from the worst-impacted regions in Italy and Spain [41]. Reportedly, the relatively low life losses associated with the COVID-19 disease in the Czech Republic can be attributed to the matter of the timing of the epidemic countermeasures [44]. In that sense, the contribution of people's fear and anxiety as a possible major force [45] driving self-isolation behaviors should be considered. Two key factors seemed to play a crucial role. These were (i) news continually brought by the 
TABLE 3: In this variant of Table 2, cells are highlighted depending on how great the difference is between SpeedDiffRel of the estimations of the prediction model and the measured values from FreeFlowSpeed. Red highlights refer to a great difference, and green highlights only to a very small one.

\begin{tabular}{|c|c|c|c|c|c|c|c|c|c|}
\hline State & Week & $\begin{array}{l}\text { All road } \\
\text { types* }\end{array}$ & $\begin{array}{l}\text { All road } \\
\text { types }^{+}\end{array}$ & Motorways* & Motorways $^{+}$ & $\begin{array}{l}\text { 1st class } \\
\text { roads }^{*}\end{array}$ & $\begin{array}{l}\text { 1stclass } \\
\text { roads }^{+}\end{array}$ & $\begin{array}{l}\text { Residential } \\
\text { area roads }\end{array}$ & $\begin{array}{l}\text { Residential } \\
\text { area roads }{ }^{+}\end{array}$ \\
\hline NS & $\begin{array}{l}24 / 2 / 2020 \\
-1 / 3 / 2020\end{array}$ & 0.21 & $1.49 \%$ & 0.83 & $8.59 \%$ & 0.17 & $1.66 \%$ & 0.2 & $0.89 \%$ \\
\hline NS & $\begin{array}{c}2 / 3 / 2020 \\
-8 / 3 / 2020\end{array}$ & 0.04 & $0.27 \%$ & 0.44 & $4.91 \%$ & 0.12 & $1.27 \%$ & 0.16 & $0.71 \%$ \\
\hline $\begin{array}{l}\text { NS } \\
\text { and ES } \\
\text { from } \\
12 / 3\end{array}$ & $\begin{array}{c}9 / 3 / 2020 \\
-15 / 3 / 2020\end{array}$ & 0.1 & $0.79 \%$ & 0.93 & $10.68 \%$ & 0.41 & $4.26 \%$ & 0.25 & $1.16 \%$ \\
\hline ES & $\begin{array}{c}16 / 3 / 2020 \\
-22 / 3 / 2020\end{array}$ & 2.04 & $15.43 \%$ & 2.11 & $24.16 \%$ & 2.42 & $25.37 \%$ & 3.43 & $15.53 \%$ \\
\hline ES & $\begin{array}{c}23 / 3 / 2020 \\
-29 / 3 / 2020\end{array}$ & 2.81 & $20.95 \%$ & 0.97 & $10.79 \%$ & 3.2 & $33.09 \%$ & 4.08 & $18.4 \%$ \\
\hline ES & $\begin{array}{l}30 / 3 / 2020 \\
-5 / 4 / 2020\end{array}$ & 2.84 & $20.61 \%$ & 0.2 & $1.91 \%$ & 3.31 & $32.79 \%$ & 3.81 & $17.19 \%$ \\
\hline ES & $\begin{array}{l}6 / 4 / 2020- \\
12 / 4 / 2020\end{array}$ & 1.65 & $12.88 \%$ & 0.49 & $5.14 \%$ & 2 & $21.7 \%$ & 2.58 & $12.18 \%$ \\
\hline ES & $\begin{array}{c}13 / 4 / 2020 \\
-19 / 4 / 2020\end{array}$ & 1.13 & $9.03 \%$ & 0.79 & $8.6 \%$ & 1.41 & $16 \%$ & 1.84 & $8.87 \%$ \\
\hline ES & $\begin{array}{c}20 / 4 / 2020 \\
-26 / 4 / 2020\end{array}$ & 0.98 & $7.43 \%$ & 0.16 & $1.6 \%$ & 1.1 & $11.67 \%$ & 1.44 & $6.66 \%$ \\
\hline ES & $\begin{array}{l}27 / 4 / 2020 \\
-3 / 5 / 2020\end{array}$ & 0.31 & $2.54 \%$ & 0.13 & $1.38 \%$ & 0.36 & $4.15 \%$ & 0.5 & $2.45 \%$ \\
\hline ES & $\begin{array}{l}4 / 5 / 2020- \\
10 / 5 / 2020\end{array}$ & 0.14 & $1.15 \%$ & 0.2 & $2.08 \%$ & 0.07 & $0.81 \%$ & 0.3 & $1.48 \%$ \\
\hline ES & $\begin{array}{c}11 / 5 / 2020 \\
-17 / 5 / 2020\end{array}$ & 0.08 & $0.61 \%$ & 0.45 & $4.44 \%$ & 0.12 & $1.25 \%$ & 0.23 & $1.08 \%$ \\
\hline NS & $\begin{array}{c}18 / 5 / 2020 \\
-24 / 5 / 2020\end{array}$ & 0.1 & $0.71 \%$ & 0.12 & $1.19 \%$ & 0.16 & $1.68 \%$ & 0.07 & $0.31 \%$ \\
\hline NS & $\begin{array}{c}25 / 5 / 2020 \\
-31 / 5 / 2020\end{array}$ & 0.03 & $0.24 \%$ & 0.24 & $2.27 \%$ & 0.01 & $0.06 \%$ & 0.14 & $0.63 \%$ \\
\hline NS & $\begin{array}{c}1 / 6 / 2020- \\
7 / 6 / 2020\end{array}$ & 0.07 & $0.50 \%$ & 0.25 & $2.4 \%$ & 0.05 & $0.46 \%$ & 0.2 & $0.9 \%$ \\
\hline
\end{tabular}

ES: emergency state; NS: normal situation. ${ }^{*}$ Relative speed difference in percentage points. ${ }^{+}$Relative speed difference in percentage points compared to the normal situation.

media and (ii) the communication strategy of the Czech government.

Regarding the former, it is well established that the media constructs reality. In the Czech case, the media was constantly broadcasting the worrying conditions observed in many European countries. This fact might have resulted in what some psychologists term "media-induced trauma" [46]. In that sense, the presented results support the hypothesis that the observed change in travel behavior might have initially (i.e., during the first three weeks) been driven mostly by individual fears and anxieties. Unfortunately, it is virtually impossible to discriminate between the effects of individual decisions taken due to media reality and due to the de jure measures of the government.

Regarding this latter aspect, the following observation should be highlighted. During the initial period, press conferences organized by the Czech government were held and broadcasted on TV very frequently, typically every day. During these conferences, information related to changes in antiepidemic measures adopted by the government was announced. Following the first three weeks of the state of emergency, the government declared the first considerable loosing of restrictions (Table 1) during such a press conference, too. The authors consider this to be a major trigger for the subsequent change in people's travel behavior.

This argument is proposed since the governmental communication strategy can be viewed as an important mechanism influencing and controlling people's behavior. By communicating the loosening of the restrictions, the government sent a positive message towards people with regard to the development of the epidemic situation. In essence, the government assured the people that the situation is getting better. As a result, from the week of 7 April 2020, people reacted by returning to their previous travel 
routines, and therefore traffic intensity gradually increased. During the week of 27 April 2020, the traffic intensity returned to the prepandemic state fully.

Considering the above findings, the authors propose the interpretation that the government broadened the gap between de jure measures and their expected or de facto effects. On the one hand, people returned to their previous travel routines rapidly. On the other hand, the state of emergency was terminated only on 17 May 2020. What this discrepancy seems to portray is that while the government intended to slowly encourage society to return back to normal (possibly due to economy-related reasons), people interpreted the above-described action in their own way. That means they reduced their self-isolation behavior almost immediately.

The observed pattern of behavior related to both the government and society seems to be crucial for analyzing the subsequent period of the COVID-19 epidemic crisis in the Czech Republic. Such an analysis is, however, beyond the scope of this article, which only stresses the importance of future research in this domain. To indicate a way forward, a recent survey conducted in the Czech Republic [47] has shown that Czech society exhibits an individualistic orientation largely, in contrast to collectivism common in many non-Western cultures (e.g., China, South Korea, and Venezuela). The influence of this factor on pandemic travel behavior deserves further attention.

In sum, an important lesson for policymakers can be formulated here. The communication related to loosening pandemic restrictions should always be crafted very carefully and with respect to cultural and behavioral nuances. Specifically, in individualistic cultures, one should not be surprised by the following pattern. Recovering from an initial shock, a significant part of society might want to prioritize their individual needs and wishes over the interest of society [47]. That means, in the absence of strong, effective, and claimable (i.e., de facto) measures, people might tend to return to their previous travel routines quite rapidly, despite the associated epidemiological risks.

5.3. Limitations and Future Research. There are two major limitations of this article. First, the presented macroperspective in Section 4 does not distinguish whether a certain road segment constitutes a part of the urban agglomeration. It is thus possible that the traffic across urban agglomerations and all road types was reduced more significantly than the average values stated in the results of the analysis focusing on a particular road type.

Second, while this study proposes certain behavior-related conclusions, those are based solely on the data showing aggregated traffic data. That means the study does not use any data collected from individuals, neither from a survey nor from interviews.

Finally, it should also be noted that while the analysis did not cover driving behavior in the pandemic times [30, 33-35], this is another promising avenue for future research. As explained in Section 2.2, the increase in achieved speeds may result in more risky driving behavior, as reported by Katrakazas et al. [35] for Greece and the Kingdom of Saudi
Arabia. This trend has also been anecdotally reported in the Czech Republic [48]. The authors are convinced it is meaningful to further explore these anecdotes in a sound way by extending the perspective presented in the study by including additional data sources about traffic violations.

\section{Appendix}

Based on the acquired average hourly speeds for individual TMC segments, SpeedDiff was calculated from the estimated values provided by the prediction model (normal situation) and the measured values from FreeFlowSpeed. Subsequently, SpeedDiffRel was calculated. Table 2 illustrates the changes in speeds arising from the weekly absolute relative differences calculated based on the prediction model and actual measurements across all Czech road types, across motorways only, $1^{\text {st }}$ class roads only, and residential area roads only. In Table 3, values with the greatest difference are highlighted in red.

\section{Data Availability}

The data used to support the findings of this study are available from the corresponding author upon reasonable request only for research purposes.

\section{Conflicts of Interest}

The authors declare that there are no conflicts of interest regarding the publication of this article.

\section{Acknowledgments}

The authors received public financial support for this research from Grant TH04010350 administered through the Technology Agency of the Czech Republic. This article was processed with support from an institutional fund (IP400040) for Long-Term Conceptual Development of Science and Research and an internal grant (F4/23/2019) at the Faculty of Informatics and Statistics of the Prague University of Economics and Business.

\section{References}

[1] C. B. Frey, C. Chen, and G. Presidente, Democracy, Culture, and Contagion: Political Regimes and Countries Responsiveness to Covid-19. 2020, Oxford University, Oxford, UK, 2020, https:// www.oxfordmartin.ox.ac.uk/downloads/academic/DemocracyCulture-and-Contagion_May13.pdf.

[2] L. Waizenegger, B. McKenna, W. Cai, and T. Bendz, "An affordance perspective of team collaboration and enforced working from home during COVID-19," European Journal of Information Systems, vol. 29, pp. 1-14, 2020.

[3] L. Budd and S. Ison, "Responsible Transport: a post-COVID agenda for transport policy and practice," Transportation Research Interdisciplinary Perspectives, vol. 6, Article ID 100151, 2020.

[4] L.-T. Zhang and S. Zhao, "Diaspora micro-influencers and COVID-19 communication on social media: the case of Chinese-speaking YouTube vloggers," Multilingua, vol. 39, no. 5, pp. 553-563, 2020. 
[5] M. Cinelli, W. Quattrociocchi, A. Galeazzi et al., "The COVID-19 social media infodemic," Scientific Reports, vol. 10, no. 1, p. 16598, 2020.

[6] M. Dalili Shoaei and M. Dastani, "The role of twitter during the COVID-19 crisis: a systematic literature review," Acta Informatica Pragensia, vol. 9, no. 2, pp. 154-169, 2020.

[7] F. J. Camacho, A. García, and E. Belda, "Analysis of impact of adverse weather on freeway free-flow speed in Spain," Transportation Research Record: Journal of the Transportation Research Board, vol. 2169, no. 1, pp. 150-159, 2010.

[8] T. Wang, J. Harvey, J. Lea, and C. Kim, "Impact of pavement roughness on vehicle free-flow speed," Journal of Transportation Engineering, vol. 140, no. 9, Article ID 04014039, 2014.

[9] Ministry of Health, COVID-19 in the Czech Republic: Open Data Sets, Ministry of Health, Prague, Czech Republic, 2020, https://onemocneni-aktualne.mzcr.cz/api/v1/covid-19.

[10] Government of the Czech Republic, Vládní Usnesení Související S Bojem Proti Epidemii Koronaviru, Government of the Czech Republic, Czechia, Europe, 2020, https://www. vlada.cz/cz/epidemie-koronaviru/dulezite-informace/prehledvladnich-usneseni-od-vyhlaseni-nouzoveho-stavu-180608/ \#brezen.

[11] Apple, Apple Mobility Trends Reports: Driving, Apple, Cupertino, CA, USA, 2021, https://covid19.apple.com/ mobility.

[12] S. Praharaj, D. King, C. Pettit, and E. Wentz, "Using aggregated mobility data to measure the effect of COVID-19 policies on mobility changes in Sydney, London, Phoenix, and Pune," Findings, 2020.

[13] J. P. Morgan, "E-commerce payments trends: Czech Republic," 2019, https://www.jpmorgan.com/europe/merchantservices/insights/reports/czech-republic.

[14] N. Baily, Apples and Pears? Comparing Google and Apple Mobility Data, Urban Big Data Centre, Glasgow, Scotland, 2020, https://www.ubdc.ac.uk/news-media/2020/may/applesand-pears-comparing-google-and-apple-mobility-data/.

[15] V. Harantová, A. Hájnik, and A. Kalašová, "Comparison of the flow rate and speed of vehicles on a representative road section before and after the implementation of measures in connection with COVID-19," Sustainability, vol. 12, no. 17, p. 7216, 2020.

[16] F. Aletta, S. Brinchi, S. Carrese et al., "Analysing urban traffic volumes and mapping noise emissions in Rome (Italy) in the context of containment measures for the COVID-19 disease," Noise Mapping, vol. 7, no. 1, pp. 114-122, 2020.

[17] P. Bucsky, "Modal share changes due to COVID-19: the case of Budapest," Transportation Research Interdisciplinary Perspectives, vol. 8, Article ID 100141, 2020.

[18] Z. Cui, "Traffic performance score for measuring the impact of COVID-19 on urban mobility," 2020, https://arxiv.org/abs/ 2007.00648.

[19] A. Marchant, What Can Traffic Data Tell Us about the Impact of the Coronavirus?, TomTom, Amsterdam, Netherlands, 2020, https://www.tomtom.com/blog/moving-world/covid19-traffic/.

[20] M. De Haas, R. Faber, and M. Hamersma, "How COVID-19 and the Dutch "intelligent lockdown" change activities, work and travel behaviour: evidence from longitudinal data in The Netherlands," Transportation Research Interdisciplinary Perspectives, vol. 6, Article ID 100150, 2020.

[21] M. J. Beck, D. A. Hensher, and E. Wei, "Slowly coming out of COVID-19 restrictions in Australia: implications for working from home and commuting trips by car and public transport,"
Journal of Transport Geography, vol. 88, Article ID 102846, 2020.

[22] T. Campisi, S. Basbas, A. Skoufas, N. Akgün, D. Ticali, and G. Tesoriere, "The impact of COVID-19 pandemic on the resilience of sustainable mobility in Sicily," Sustainability, vol. 12, no. 21, p. 8829, 2020.

[23] S. Shakibaei, G. C. De Jong, P. Alpkökin, and T. H. Rashidi, "Impact of the COVID-19 pandemic on travel behavior in Istanbul: a panel data analysis," Sustainable Cities and Society, vol. 65, Article ID 102619, 2021.

[24] A. Aloi, B. Alonso, J. Benavente et al., "Effects of the COVID19 lockdown on urban mobility: empirical evidence from the city of Santander (Spain)," Sustainability, vol. 12, no. 9, p. $3870,2020$.

[25] E. Jenelius and M. Cebecauer, "Impacts of COVID-19 on public transport ridership in Sweden: analysis of ticket validations, sales and passenger counts," Transportation Research Interdisciplinary Perspectives, vol. 8, Article ID 100242, 2020.

[26] A. Przybylowski, S. Stelmak, and M. Suchanek, "Mobility behaviour in view of the impact of the COVID-19 pandemicpublic transport users in Gdansk case study," Sustainability, vol. 13, no. 1, p. 364, 2021.

[27] D. S. Pawar, A. K. Yadav, N. Akolekar, and N. R. Velaga, "Impact of physical distancing due to novel coronavirus (SARS-CoV-2) on daily travel for work during transition to lockdown," Transportation Research Interdisciplinary Perspectives, vol. 7, Article ID 100203, 2020.

[28] E. Mogaji, "Impact of COVID-19 on transportation in Lagos, Nigeria," Transportation Research Interdisciplinary Perspectives, vol. 6, Article ID 100154, 2020.

[29] G. Parady, A. Taniguchi, and K. Takami, "Travel behavior changes during the COVID-19 pandemic in Japan: analyzing the effects of risk perception and social influence on going-out self-restriction," Transportation Research Interdisciplinary Perspectives, vol. 7, Article ID 100181, 2020.

[30] A. Shamshiripour, E. Rahimi, R. Shabanpour, A. Mohammadian, and Kouros), "How is COVID-19 reshaping activity-travel behavior? Evidence from a comprehensive survey in Chicago," Transportation Research Interdisciplinary Perspectives, vol. 7, Article ID 100216, 2020.

[31] M. P. Poelman, M. Gillebaart, C. Schlinkert et al., "Eating behavior and food purchases during the COVID-19 lockdown: a cross-sectional study among adults in The Netherlands," Appetite, vol. 157, Article ID 105002, 2020.

[32] A. Pani, S. Mishra, M. Golias, and M. Figliozzi, "Evaluating public acceptance of autonomous delivery robots during COVID-19 pandemic," Transportation Research Part D: Transport and Environment, vol. 89, Article ID 102600, 2020.

[33] E. Vingilis, D. Beirness, P. Boase et al., "Coronavirus disease 2019: what could be the effects on road safety?" Accident Analysis \& Prevention, vol. 144, Article ID 105687, 2020.

[34] D. Stavrinos, B. McManus, S. Mrug et al., "Adolescent driving behavior before and during restrictions related to COVID19," Accident Analysis \& Prevention, vol. 144, Article ID 105686, 2020.

[35] C. Katrakazas, E. Michelaraki, M. Sekadakis, and G. Yannis, "A descriptive analysis of the effect of the COVID-19 pandemic on driving behavior and road safety," Transportation Research Interdisciplinary Perspectives, vol. 7, Article ID 100186, 2020.

[36] RSD, Sčítání Dopravy, Stupně Provozu a Detekce Kolon, RSD, Geneva, Switzerland, 2020, http://portal.dopravniinfo.cz/ telematicke-aplikace/scitani-dopravy-stupne-provozu-a-detekcekolon. 
[37] R. Jonák, Z. Smutný, M. Šimůnek, and M. Doležel, "Route and travel time optimization for delivery and utility services: an industrial viewpoint," Acta Informatica Pragensia, vol. 9, no. 2, pp. 200-209, 2020.

[38] M. Simunek and Z. Smutny, "Traffic information enrichment: creating long-term traffic speed prediction ensemble model for better navigation through waypoints," Applied Sciences, vol. 11, no. 1, p. 315, 2021.

[39] D. Zang, Y. Fang, D. Wang, Z. Wei, K. Tang, and X. Li, "Long term traffic flow prediction using residual net and deconvolutional neural network," in Pattern Recognition and Computer Vision, pp. 62-74, Springer, Berlin, Germany, 2018.

[40] M. Cao, V. O. K. Li, and V. W. S. Chan, "A CNN-LSTM model for traffic speed prediction," in Proceedings of the 2020 IEEE 91st Vehicular Technology Conference (VTC2020-Spring), May 2020.

[41] O. Mitjà, À. Arenas, X. Rodó, A. Tobias, J. Brew, and J. M. Benlloch, "Experts' request to the Spanish government: move Spain towards complete lockdown," The Lancet, vol. 395, no. 10231, pp. 1193-1194, 2020.

[42] D. Xu, "Physical mobility under stay-at-home orders: a comparative analysis of movement restrictions between the U.S. and europe," Economics \& Human Biology, vol. 40, Article ID 100936, 2021.

[43] G. Hauck, L. Reyes, and J. L. Ortiz, Stay Home, Stay Healthy:" These States have Ordered Residents to Avoid Nonessential Travel Amid Coronavirus. 2020, The Courier-Journal, Louisville, KY, USA, 2020, https://eu.courier-journal.com/ story/news/nation/2020/03/21/coronavirus-lockdown-ordersshelter-place-stay-home-state-list/2891193001/.

[44] P. Widimsky, J. Benes, and A. M. Celko, "Czech Republic and low COVID-19 mortality in the heart of Europe: possible explanations," European Heart Journal, vol. 41, no. 40, pp. 3876-3879, 2020.

[45] F. Ornell, J. B. Schuch, A. O. Sordi, and F. H. P. Kessler, "'Pandemic fear" and COVID-19: mental health burden and strategies," Brazilian Journal of Psychiatry, vol. 42, no. 3, pp. 232-235, 2020.

[46] R. Trnka and R. Lorencova, "Fear, anger, and media-induced trauma during the outbreak of COVID-19 in the Czech Republic," Psychological Trauma: Theory, Research, Practice, and Policy, vol. 12, no. 5, pp. 546-549, 2020.

[47] H. Hnilicova, K. Dobiasova, and E. Tulupova, Behavioralní Aspekty Pandemie COVID-19v ČR. 2021, Communicated at Press Conference of Czech Medical Association of J.E. Purkyně, Prague, Czech Republic, 2021.

[48] V. Janous and K. Vanickova, Smrt Na Prázdné Silnici, Mladá Fronta DNES, Prague, Czech Republic, 2020. 